NBER WORKING PAPER SERIES

THE RATE OF RETURN TO THE HIGH/SCOPE PERRY PRESCHOOL PROGRAM

\author{
James J. Heckman \\ Seong Hyeok Moon \\ Rodrigo Pinto \\ Peter A. Savelyev \\ Adam Yavitz \\ Working Paper 15471 \\ http://www.nber.org/papers/w15471 \\ NATIONAL BUREAU OF ECONOMIC RESEARCH \\ 1050 Massachusetts Avenue \\ Cambridge, MA 02138 \\ November 2009
}

We are grateful to Lena Malofeeva and Larry Schweinhart of the High/Scope Foundation for their comments and their continued support of our ongoing collaboration. We are grateful to Dennis Epple, and two anonymous referees for their comments and to Steve Durlauf, Jeff Grogger and participants at the Public Policy and Economics seminar at the Harris School, University of Chicago, March, 2009. This research was supported by the Committee for Economic Development by a grant from the Pew Charitable Trusts and the Partnership for America's Economic Success (PAES); the JB \& MK Pritzker Family Foundation; Susan Thompson Buffett Foundation; and NICHD (R01HD043411). The views expressed in this presentation are those of the authors and not necessarily those of the funders listed here. Supplementary materials may be retrieved from http://jenni.uchicago.edu/Perry/cba/. The views expressed herein are those of the author(s) and do not necessarily reflect the views of the National Bureau of Economic Research.

NBER working papers are circulated for discussion and comment purposes. They have not been peerreviewed or been subject to the review by the NBER Board of Directors that accompanies official NBER publications.

(C) 2009 by James J. Heckman, Seong Hyeok Moon, Rodrigo Pinto, Peter A. Savelyev, and Adam Yavitz. All rights reserved. Short sections of text, not to exceed two paragraphs, may be quoted without explicit permission provided that full credit, including $\odot$ notice, is given to the source. 
The Rate of Return to the High/Scope Perry Preschool Program

James J. Heckman, Seong Hyeok Moon, Rodrigo Pinto, Peter A. Savelyev, and Adam Yavitz

NBER Working Paper No. 15471

November 2009

JEL No. D62,I22,I28

\begin{abstract}
$\underline{\text { ABSTRACT }}$
This paper estimates the rate of return to the High/Scope Perry Preschool Program, an early intervention program targeted toward disadvantaged African-American youth. Estimates of the rate of return to the Perry program are widely cited to support the claim of substantial economic benefits from preschool education programs. Previous studies of the rate of return to this program ignore the compromises that occurred in the randomization protocol. They do not report standard errors. The rates of return estimated in this paper account for these factors. We conduct an extensive analysis of sensitivity to alternative plausible assumptions. Estimated social rates of return generally fall between 7-10 percent, with most estimates substantially lower than those previously reported in the literature. However, returns are generally statistically significantly different from zero for both males and females and are above the historical return on equity. Estimated benefit-to-cost ratios support this conclusion.
\end{abstract}

James J. Heckman

Department of Economics

The University of Chicago

1126 E. 59th Street

Chicago, IL 60637

and NBER

jjh@uchicago.edu

Seong Hyeok Moon

Department of Economics

The University of Chicago

1126 E. 59th Street

Chicago, IL 60637

moon@uchicago.edu

Rodrigo Pinto

Department of Economics

The University of Chicago

1126 E. 59th Street

Chicago, IL 60637

rodrig@uchicago.edu
Peter A. Savelyev

Department of Economics

University of Chicago

1126 E. 59th Street

Chicago, IL 60637

psavel@uchicago.edu

Adam Yavitz

Department of Economics

University of Chicago

1126 E. 59th Street

Chicago, IL 60637

adamy@uchicago.edu 


\title{
The Rate of Return to the High/Scope Perry Preschool Program
}

\author{
James J. Heckman ${ }^{\mathrm{a}, 1,2}$, Seong Hyeok Moon ${ }^{\mathrm{a}, 3}$, Rodrigo Pinto ${ }^{\mathrm{a}, 3}$, Peter A. \\ Savelyev $^{\mathrm{a}, 3}$, Adam Yavitz ${ }^{\mathrm{a}, 4}$ \\ ${ }^{a}$ Department of Economics, University of Chicago, 1126 East 59th Street, Chicago, \\ Illinois 60637
}

\begin{abstract}
This paper estimates the rate of return to the High/Scope Perry Preschool Program, an early intervention program targeted toward disadvantaged AfricanAmerican youth. Estimates of the rate of return to the Perry program are widely cited to support the claim of substantial economic benefits from preschool education programs. Previous studies of the rate of return to this program ignore the compromises that occurred in the randomization protocol. They do not report standard errors. The rates of return estimated in this paper account for these factors. We conduct an extensive analysis of sensitivity to alternative plausible assumptions. Estimated social rates of return generally fall between $7-10$ percent, with most estimates substantially

Email addresses: jjh@uchicago.edu (James J. Heckman), moon@uchicago.edu (Seong Hyeok Moon), rodrig@uchicago.edu (Rodrigo Pinto), psavel@uchicago.edu (Peter A. Savelyev), adamy@uchicago.edu (Adam Yavitz)

${ }^{1}$ Corresponding author Henry Schultz Distinguished Service Professor of Economics at the University of Chicago, Professor of Science and Society, University College Dublin, Alfred Cowles Distinguished Visiting Professor, Cowles Foundation, Yale University and Senior Fellow, American Bar Foundation.

${ }^{2}$ Telephone: (773) 702-0634, Fax: (773) 702-8490.

${ }^{3}$ Ph.D. candidate, Department of Economics, University of Chicago.

${ }^{4}$ Research Professional at Economic Research Center, University of Chicago.
\end{abstract}

October 27, 2009 
lower than those previously reported in the literature. However, returns are generally statistically significantly different from zero for both males and females and are above the historical return on equity. Estimated benefit-to-cost ratios support this conclusion.

Key words: rate of return, cost-benefit analysis, standard errors, Perry

Preschool Program, compromised randomization, early childhood

intervention programs, deadweight costs

JEL Codes: D62, I22, I28.

\section{Introduction}

President Barack Obama has actively promoted early childhood education as a way to foster economic efficiency and reduce inequality. ${ }^{5}$ He has also endorsed accountability and transparency in government. ${ }^{6}$ In an era of tight budgets and fiscal austerity, it is important to prioritize expenditure and use funds wisely. As the size of government expands, there is a renewed demand for cost-benefit analyses to weed out political pork from economically productive programs. $^{7}$

The economic case for expanding preschool education for disadvantaged children is largely based on evidence from the High/Scope Perry Preschool Program, an early intervention in the lives of disadvantaged children in the

\footnotetext{
${ }^{5}$ See Dillon (2008).

${ }^{6}$ Weekly address of the President, January 31, 2009, as cited in Bajaj and Labaton (2009).

${ }^{7}$ The McArthur Foundation has recently launched an initiative to promote the application of cost-benefit analysis in the service of making government effective. See Fanton (2008).
} 
early 1960 s. $^{8}$ In that program, children were randomly assigned to treatment and control group status and have been systematically followed through age 40. Information on earnings, employment, education, crime and a variety of other outcomes are collected at various ages of the study participants. In a highly cited paper, Rolnick and Grunewald (2003) report a rate of return of 16 percent to the Perry program. Belfield et al. (2006) report a 17 percent rate of return.

Critics of the Perry program point to the small sample size of the evaluation study (123 treatments and controls), the lack of a substantial long-term effect of the program on IQ, and the absence of statistical significance for many estimated treatment effects. ${ }^{9}$ Hanushek and Lindseth (2009) question the strength of the evidence on the Perry program, claiming that estimates of its impact are fragile.

The literature does little to assuage these concerns. All of the reported estimates of rates of return are presented without standard errors, leaving readers uncertain as to whether the estimates are statistically significantly different from zero. The paper by Rolnick and Grunewald (2003) reports few details and no sensitivity analyses exploring the consequences of alternative assumptions about costs and benefits of key public programs and the costs of crime. The study by Belfield et al. (2006) also does not report standard er-

\footnotetext{
${ }^{8}$ See, e.g., Shonkoff and Phillips (2000) or Karoly et al. (2005). No other early childhood intervention has a follow-up into adult life as late as the Perry program. For example, the benefit-cost study of the Abecedarian Program only follows people to age 21, and relies heavily on extrapolation of future earnings (Barnett and Masse, 2007).

${ }^{9}$ See Herrnstein and Murray (1994, pp.404-405). Heckman, Moon, Pinto, Savelyev, and Yavitz (2009b) show statistically significant treatment effects for males and females using small sample permutation tests. They also find close agreement between small sample tests and large sample tests in the Perry sample.
} 
rors. It provides more details on how its estimates are obtained, but conducts only a limited sensitivity analysis.

Any computation of the lifetime rate of return to the Perry program must address four major challenges: (a) the randomization protocol was compromised; (b) there are no data on participants past age 40 and it is necessary to extrapolate out-of-sample to obtain earnings profiles past that age to estimate lifetime impacts of the program; (c) some data are missing for participants prior to age 40; and (d) there is difficulty in assigning reliable values to non-market outcomes such as crime. The last point is especially relevant to any analysis of the Perry program because crime reduction is one of its major benefits. Unless these challenges are carefully addressed, the true rate of return remains uncertain as does the economic case for early intervention.

This paper presents rigorous estimates of the rate of return and the benefit-to-cost ratio for the Perry program. Our analysis improves on previous studies in seven ways. (1) We account for compromised randomization in evaluating this program. As noted in Heckman, Moon, Pinto, Savelyev, and Yavitz (2009b), in the Perry study, the randomization actually implemented in this program is somewhat problematic because of reassignment of treatment and control status after random assignment. (2) We develop standard errors for all of our estimates of the rate of return and for the benefit-to-cost ratios accounting for components of the model where standard errors can be reliably determined. (3) For the remaining components of costs and benefits where meaningful standard errors cannot be determined, we examine the sensitivity of estimates of rates of return to plausible ranges of assumptions. 
(4) We present estimates that adjust for the deadweight costs of taxation. Previous estimates ignore the costs of raising taxes in financing programs. (5) We use a much wider variety of methods to impute within-sample missing earnings than have been used in the previous literature, and examine the sensitivity of our estimates to the application of alternative imputation procedures that draw on standard methods in the literature on panel data. ${ }^{10}$ (6) We use state-of-the-art methods to extrapolate missing future earnings for both treatment and control group participants. We examine the sensitivity of our estimates to plausible alternative assumptions about out-of-sample earnings. We also report estimates to age 40 that do not require extrapolation. (7) We use local data on costs of education, crime, and welfare participation whenever possible, instead of following earlier studies in using national data to estimate these components of the rate of return.

Table 1 summarizes the range of estimates from our preferred methodology, defended later in this paper. Estimates from a diverse set of methodologies can be found in Web Appendix J. All point in the same direction. Separate rates of return are reported for benefits accruing to individuals versus those that accrue to society at large that include the impact of the program on crime, participation in welfare, and the resulting savings in social costs. Our estimate of the overall social rate of return to the Perry program is in the range of 7-10 percent. We report a range of estimates because of uncertainty about some components of benefits and costs for which standard

\footnotetext{
${ }^{10}$ See, e.g., MaCurdy (2007) for a survey of these methods.
} 


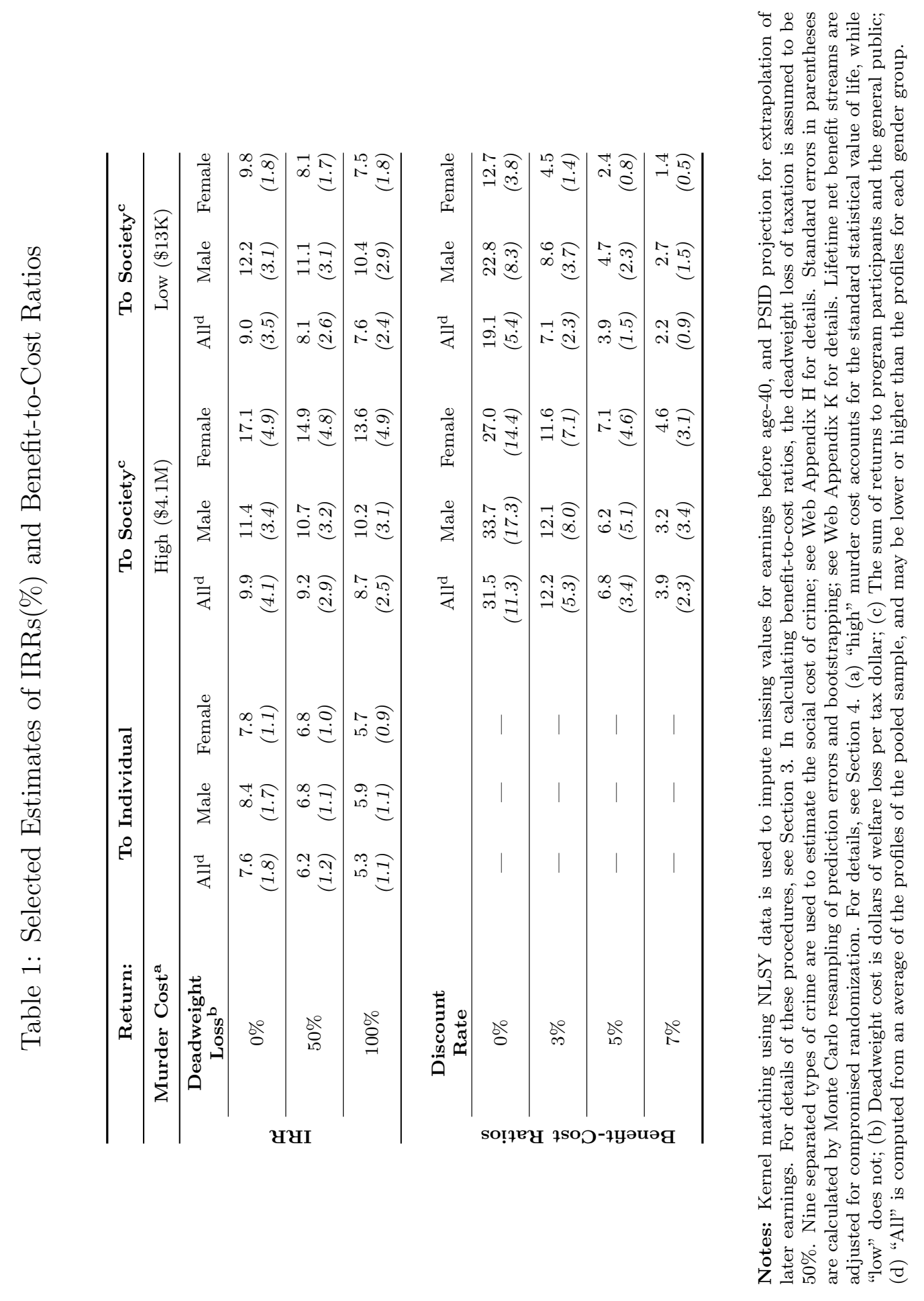


errors cannot be assigned. These estimates are above the historical return to equity. ${ }^{11}$ However, our estimates are substantially below the estimates of the rate of return to the Perry program reported in previous studies. This difference is driven mainly by our approach to evaluating the social costs of crime. We present an extensive sensitivity analysis of the consequences of alternative assumptions about the social cost of crime for the estimated rate of return. The benefit-to-cost ratios presented in the bottom of Table 1 support the rate of return analysis. The rest of the paper justifies the estimates presented in Table 1.

This paper proceeds in the following way. Section 2 discusses the Perry program and how it was evaluated. Section 3 discusses the sampling plan used to collect the outcomes of the experiment and the empirical problems it creates, which require imputation and extrapolation to compute the rate of return. Problems of estimating non-market benefits of the program are also discussed. Section 4 presents our estimates and their sensitivity to alternative plausible assumptions. We contrast our approach with the approaches taken by other analysts. In the final section, we summarize our findings and draw conclusions.

\footnotetext{
${ }^{11}$ The estimated mean returns are above the post-World War II stock market rate of return on equity of 5.8 percent (see DeLong and Magin, 2009).
} 


\section{Perry: Experimental Design and Background}

The High/Scope Perry Preschool Program was an early childhood education program conducted at the Perry Elementary School in Ypsilanti, Michigan, during the early 1960s. Beginning at age three and lasting two years, treatment consisted of a 2.5-hour preschool program on weekdays during the school year, supplemented by weekly home visits by teachers.

The curriculum was based on supporting children's cognitive and socioemotional development through active learning where both teachers and children had major roles in shaping children's learning. Children were encouraged to plan, carry out, and reflect on their own activities through a plan-doreview process. Adults observed, supported, and extended children's play as appropriate. They also encouraged children to make choices, problem solve, and engage in activities. Instead of providing lessons, Perry emphasized reflective and open-ended questions asked by teachers. Examples are: "What happened? How did you make that? Can you show me? Can you help another child?" (Schweinhart, Barnes, and Weikart, 1993, p. 33). ${ }^{12}$

Eligibility Criteria. Five cohorts of preschoolers were enrolled in the program in the early to the mid-1960's. Drawn from the community served by the Perry Elementary School, participants were located through a survey of families associated with that school, as well as through neighborhood

\footnotetext{
${ }^{12}$ Web Appendix A provides further information on the program. See http://jenni. uchicago.edu/Perry/cba/.
} 
group referrals, and door-to-door canvassing. Disadvantaged children living in adverse circumstances were identified using IQ scores and a family socioeconomic status (SES) index. Those with IQ scores outside the range of 70-85 were excluded, as were those with untreatable mental defects.

The Compromised Randomization Protocol. A potential problem with the Perry study is that after random assignment, treatment and controls were reassigned, compromising the original random assignment and making simple interpretation of the evidence problematic. In addition, there was some imbalance in the baseline variables between treatment and control groups. Heckman, Moon, Pinto, Savelyev, and Yavitz (2009b) discuss the Perry selection and randomization protocols in detail. They correct for the imbalance in preprogram variables and the compromise in randomization using matching. We use their procedures in this analysis. ${ }^{13}$

\footnotetext{
${ }^{13}$ The randomization protocol used in the Perry Preschool Program was complex. For each designated eligible entry cohort, children were assigned to treatment and control groups in the following way. (1) Participant status of the younger siblings is the same as that of their older siblings; (2) Those remaining were ranked by their entry IQ score with odd- and even-ranked subjects assigned to separate groups; (3) Some individuals initially assigned to one group were swapped between groups to balance gender and mean SES scores, "with Standford-Binet scores held more or less constant". This produced an imbalance in family background variables; (4) A coin toss randomly selected one group as the treatment group and the other as the control group; (5) Some individuals provisionally assigned to treatment, whose mothers were employed at the time of the assignment, were swapped with control individuals whose mothers were not employed. The rationale for this swap was that it was difficult for working mothers to participate in home visits assigned to the treatment group. For further discussion of the Perry randomization protocol, see Appendix L and Heckman, Moon, Pinto, Savelyev, and Yavitz (2009b).
} 
Evidence on Selective Participation. Weikart et al. (1978) claim that "virtually all" eligible families agreed to participate in the program, implying that there is no issue of bias arising from selective participation of more motivated families from the pool of eligible participants. ${ }^{14}$

Study Follow-Up. Follow-up interviews were conducted when participants were approximately 15, 19, 27, and 40 years old. Attrition remains low throughout the study, with over 90 percent of the original sample participating in the age-40 interview. At these interviews, participants provided detailed information about their lifecycle trajectories including schooling, economic activity, marital life, child rearing, and incarceration. In addition, Perry researchers collect administrative data in the form of school records, police and court records, and welfare program participation records.

The Previous Literature and Its Critics. As the oldest and most cited early childhood intervention evaluated by the method of random assignment, the Perry study serves as a flagship for policy makers advocating public support for early childhood programs. Schweinhart et al. (2005) and Heckman, Moon, Pinto, Savelyev, and Yavitz (2009b) find substantial treatment ef-

\footnotetext{
${ }^{14}$ Heckman, Moon, Pinto, Savelyev, and Yavitz (2009b) discuss the external validity of the Perry study. Using the NLSY sample of African Americans who were born in the same years as the Perry participants, they estimate that $17 \%$ of the males and $15 \%$ of the females in the NLSY would be eligible for the Perry program if it were applied nationwide. Perry over-represents the most disadvantaged segment of the African-American population of children.
} 
fects. Crime reduction is a major benefit of this program. ${ }^{15}$ The latter study systematically addresses several important statistical issues that arise in analyzing the Perry data including its small sample size. The authors show that for the Perry data small sample permutation inference (based on randomly assigning treatment labels for treatments and controls) produces the same inference about the null hypothesis of no treatment effect as is produced from application of test statistics that are justified only in large samples. Thus, concerns over the small sample size of the Perry study are unfounded.

Table 2 presents some descriptive statistics on treatment-control differences. Additional detail about the program can be found on the Web Appendix for this paper.

For the cost-benefit analysis of this program, the High/Scope Foundation collaborated with outside researchers and produced cost-benefit analyses for the age-27 and age-40 follow-up studies. ${ }^{16}$ An independent study was conducted by Rolnick and Grunewald (2003). These studies report high internal rates of return (IRR): 16 percent by Rolnick and Grunewald (2003) and 17 percent by Belfield et al. (2006). Our analysis challenges these estimates. Unlike the estimates reported in previous studies, our estimated rates of return recognize problems with the data and problems raised by imbalances in

\footnotetext{
${ }^{15}$ Their findings are generally consistent with findings from a recent study of Head Start (Garces et al., 2002). Those authors find that African-Americans who participated in Head Start are significantly less likely to have been booked or charged with a crime.

${ }^{16}$ Barnett (1996) and Belfield, Nores, Barnett, and Schweinhart (2006), respectively.
} 
Table 2: Descriptive Statistics

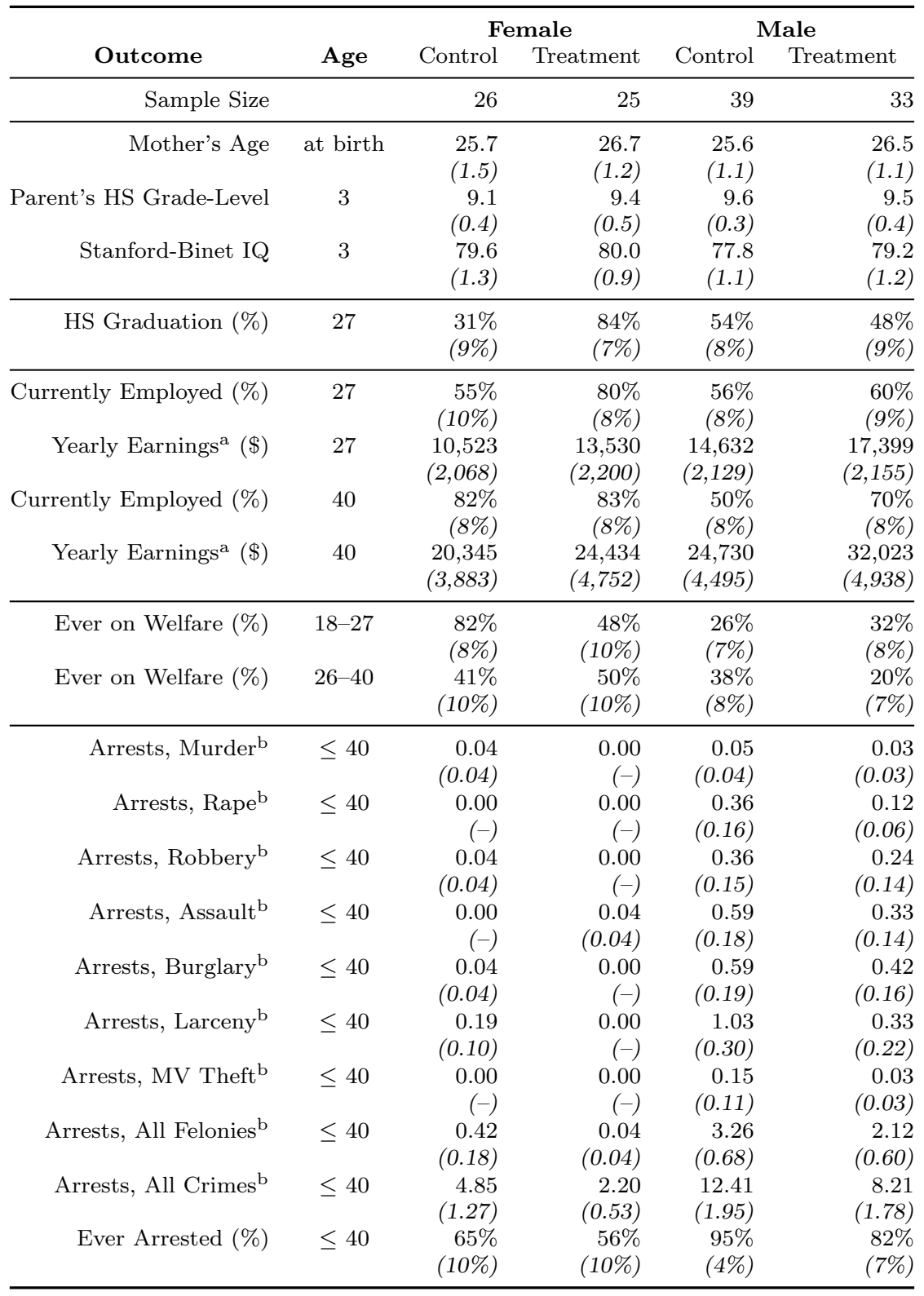

Notes: Numbers in parentheses are standard errors. (a) In year-2006 dollars; (b) Mean occurrence. Source: Perry Preschool data. See Schweinhart et al. (2005). 
preprogram variables between treatments and controls and by compromised randomization. The previous studies are unable to answer many important questions: How reliable are the IRR estimates? Can we conclude that the estimated IRRs are statistically significantly different from zero? Are all assumptions, accounting rules and estimation methods employed in previous studies reasonable? How would different plausible earnings imputation and extrapolation methods impact estimates of the IRR? If crime costs drive the IRR results, as previous studies have found, what are the consequences of estimating these costs under different plausible assumptions?

\section{Program Costs and Benefits}

The internal rate of return (IRR) is the annualized rate of return that equates the present values of costs and benefits between treatment and control group members. Lifetime benefits and costs through age 40 are directly measured using follow-up interviews. Extrapolation can be used to extend these profiles through age 65 . Alternatively, we also compute rates of return through age 40 to eliminate uncertainty due to extrapolation. The scope of our evaluation is confined to the costs and benefits of education, earnings, criminal behavior, tax payments, and reliance on public welfare programs. There are no reliable data on health outcomes, marital and parental outcomes, the quality of social life and the like. ${ }^{17}$ Hence, our estimated rate of

\footnotetext{
${ }^{17}$ Appendix B summarizes the data sources which we use in this paper.
} 
return likely understates the true rate of return, although we have no direct evidence on this issue. We present separate estimates of rates of return for private benefits and more inclusive social benefits.

\subsection{Initial Program Cost}

We use estimates of initial program costs reported in Barnett (1996). These include both operating costs (teacher salaries and administrative costs) and capital costs (classrooms and facilities). This information is summarized in Web Appendix C. In undiscounted year-2006 dollars, cost of the program per child is $\$ 17,759$.

\subsection{Program Benefits: Education}

Perry promoted educational attainment through two avenues: total years of education attained and rates of progression to a given level of education. This pattern is particularly evident for females. Treated females received less special education, progressed more quickly through grades, earned higher GPAs, and attained higher levels of education than their controlgroup counterparts. The statistical significance of these differences depends on the methodology used, but all results point in the same direction. For males, however, the impact of the program on schooling attainment is weak at best. ${ }^{18}$

\footnotetext{
${ }^{18}$ This pattern was noted in Heckman (2005). Heckman, Moon, Pinto, Savelyev, and Yavitz (2009b) discuss this phenomenon in the context of the local labor market in which Perry participants reside. In the late 1970s, as Perry participants entered the workforce, the local male-friendly high-wage automotive manufacturing sector was booming. Persons
} 
In this section, we report estimates of tuition and other pecuniary costs paid by individuals to regular K-12 educational institutions, colleges, and vocational training institutions, and additional social costs incurred by society to educate them. ${ }^{19}$ The amount of educational expenditure that the general public spends is greater if persons attain more schooling or if they progress through school less efficiently. Web Appendix D presents detailed information on educational attainment and costs in Perry.

K-12 Education. To calculate the cost of K-12 education, we assume that all Perry subjects went to public school at the annual cost per pupil in the state of Michigan during the period in question, $\$ 6,645 .{ }^{20}$ Treatment group members spent only slightly more time in the K-12 system, in spite of the discrepancy between treatment and control group graduation rates. Among females, control subjects were held back in school more often. This equalized the social cost of educating them in the K-12 system with the social cost of the treatment group. Society spent comparable amounts of resources on individuals during their K-12 education regardless of their treatment experience, albeit for different reasons. Most treatment females who stayed longer

did not need high school diplomas to get good entry-level jobs in manufacturing. (See Goldin and Katz, 2008.)

${ }^{19}$ All monetary values are in year-2006 dollars unless otherwise specified. Social costs include the additional funds beyond tuition paid required to educate students.

${ }^{20}$ See "Total expenditure per pupil in public elementary and secondary education" for years 1974-1980, as reported by the Digest of Education Statistics (1975-1982, each year, in year-2006 dollars). We assume that public K-12 education entails no private cost for individuals. Detailed per pupil expenditures for Ypsilanti schools are not available for the relevant years. 
obtained diplomas, while most control females who stayed longer repeated grades and many eventually dropped out of school. For males, educational experiences were very similar between treatments and controls.

GED and Special Education. Some male dropouts acquired high school certificates through GED testing. Our estimates of the private costs of K-12 education include the cost of getting a GED. ${ }^{21}$ Female control subjects received more special education than treatment subjects. For males, there was no difference in receipt of special education by treatment status. Special services require additional spending. To calculate this cost, we use estimates from Chambers, Parrish, and Harr (2004), who provide a historical trend of the ratio of per-pupil costs for special and regular education. ${ }^{22}$

2- and 4-Year Colleges. To calculate the cost of college education, we use each individual's record of credit hours attempted multiplied by the cost per credit hour (including both student-paid tuition costs and public institutional expenditures), taking into account the type of college attended. ${ }^{23}$ Male con-

\footnotetext{
${ }^{21}$ For detailed statistics about the GED, see Heckman and LaFontaine (2008).

${ }^{22}$ In $1968-69$, this ratio was about 1.92 ; in $1977-78$, it was 2.17 . Since Perry subjects attended K-12 education in the interval between these two periods, we set the ratio to 2 and apply it to all K-12 schooling years, which gives an additional $\$ 6,645$ annual per-pupil cost for special education.

${ }^{23}$ Total cost is the sum of private tuition and public expenditure. For student-paid tuition costs at a 2-year college, we use the 1985 tuition per credit hour for Washtenaw Community College (\$29); for a 4-year college, that of Michigan State University for the same year (\$42). To calculate public institutional expenditure per credit hour, we divide the national mean of total per-student annual expenditure (National Center for Education Statistics, 1991, "Expenditure per Full-Time-Equivalent Student", Table 298) by 30, a typical credit-hour requirement for full-time students at U.S. colleges. This calculation yields $\$ 590$ per credit hour for 2-year colleges and $\$ 1,765$ for 4 -year colleges.
} 
trol subjects attended more college classes than male treatment subjects the reverse of the pattern for females. As a result, the social cost of college education is bigger for the control group among males while it is bigger for the treatment group among females.

After the age-27 interview, many Perry subjects progressed to higher education. Without having detailed information about educational attainment between the age-27 and age-40 interviews, we make some crude cost estimates. For college education, we assume "some college education" to be equivalent to 1-year attendance at a 2-year college. For 2-year or 4-year college degrees, we take the tuition and expenditure estimates used for college going before age $27 .^{24}$ Without detailed information on whether a subject did or did not get any financial support, we assume that the private cost for a 2-year master's degree is the same as that for a 4-year bachelor's degree. Control males and treatment females pursued higher education more vigorously than did their same-sex counterparts, although only the treatment effect for females is statistically significant.

Vocational Training. Some subjects attended vocational training programs. Among males, control group members were more likely to attend vocational programs, although the treatment effect is not precisely determined. Among females, the pattern is reversed and the treatment effect is precisely determined. Thus, the public spent more resources to train control males and

\footnotetext{
${ }^{24}$ For missing information on educational attainment, we use the corresponding gendertreatment group mean.
} 
treatment females than their respective counterparts. ${ }^{25}$ Individual costs are calculated using the number of months each Perry subject attended a vocational training institute. Table 3 summarizes the components of estimated educational costs. The other components of costs and benefits are discussed later.

\subsection{Program Benefits: Employment and Earnings}

To construct lifetime earnings profiles, we must solve two practical problems. First, job histories were constructed retrospectively only for a fixed number of previous job spells. ${ }^{26}$ Missing data must be imputed using econometric techniques. Second, data on the Perry sample ends at the time of the age-40 interview. In order to generate lifetime profiles, it is necessary to predict earnings profiles beyond this age or else to estimate rates of return through age 40. The latter assumption is conservative in assuming no persistence of treatment effects past age 40. We report both sets of estimates in this paper. The proportion of non-missing earnings data is about only 70

\footnotetext{
${ }^{25}$ We assume that all costs are paid by the general public. Estimates by Tsang (1997) suggest per-trainee costs which are 1.8 times the per-pupil costs of regular high school education.

${ }^{26}$ At each interview, participants were asked to provide information about their employment history and earnings at each job for several previous jobs. From this interview design, three problems arise. First, for people with high job mobility, some past jobs are unreported. Second, for people who were interviewed in the middle of a job spell, it may not be possible to precisely specify the end point of that job spell - that is, we have a "right-censoring" problem for the job spells at the time of interview. Third, even when the dates for each job spell can be precisely specified, it is not possible to identify how earning profiles evolve within each job spell because an interviewee reports only one earnings value for each job.
} 
percent for ages 19-40. Web Appendix G presents descriptive statistics and the procedures used to extrapolate earnings when extrapolation is used.

Imputation. To impute missing values for periods prior to the age-40 interview, we use four different imputation procedures and compare the estimates based on them. First, we use simple piecewise linear interpolation, based on weighted averages of the nearest observed data points around a missing value. This approach is used by Belfield, Nores, Barnett, and Schweinhart (2006). For truncated spells, ${ }^{27}$ we first impute missing employment status with the mean of the corresponding gender-treatment data from the available sample at the relevant time period, and then we interpolate. Second, we impute missing values using estimated earnings functions fit on a matched 1979 National Longitudinal Survey of Youth (NLSY79) "low-ability" 28 African-American subsample of the same age as Perry subjects. Heckman, Moon, Pinto, Savelyev, and Yavitz (2009b) show that this subsample from the NLSY79 is similar in characteristics and outcomes to the Perry controls. The NLSY79 longitudinal data are far more complete than the Perry data. We estimate earnings functions for each NLSY79 gender-age cross-section using education

\footnotetext{
${ }^{27}$ As noted in the previous footnote, there are job spells in progress at the time of interview.

${ }^{28}$ This "low-ability" subsample is selected by initial background characteristics that mimic the eligibility rule actually used in the Perry program. NLSY79 is a nationallyrepresentative longitudinal survey whose respondents are almost at the same age (birth years 1956-1964) as the Perry sample (birth years 1957-1962). We extract a comparison group from this data using birth order, socioeconomic status (SES) index, and AFQT test score. These restrictions are chosen to mimic the program eligibility criteria of the Perry study. For details, see Web Appendix F.
} 
dummies, work experience and its square as regressors and then impute from this equation the missing values for the corresponding Perry gender-age crosssection. For truncated spells, we assume symmetry around the truncation points. Third, we use a kernel procedure that matches each Perry subject to similar observations in the NLSY79 sample to impute missing values in Perry. Each Perry subject is matched to all observations in the NLSY79 comparison group sample, but with different weights that depend on a measure of distance in characteristics between Perry experimentals, and comparison group members. ${ }^{29}$ This procedure weights more heavily NLSY sample participants who more closely match Perry subjects. For truncated spells, we first match the length of spells, and then earnings. Fourth, we estimate dynamic earnings functions using the method of Hause (1980), discussed by MaCurdy (2007), for each NLSY79 age-gender group. This procedure decomposes individual earnings processes into observed abilities, unobserved time-invariant components and serially correlated shocks. The procedure uses the estimated parameters of the Hause model to impute missing values in the Perry earnings data. For truncated spells, we assume symmetry around truncation points. All four methods are conservative in that they impose the same earnings structure on the missing data for treatment and controls. The fourth method preserves differences in pre-existing patterns of unobservables between treatments and controls. See Appendix G for further

\footnotetext{
${ }^{29}$ We use the Mahalanobis (1936) distance.
} 
discussion.

Extrapolation. Given the absence of earnings data after age 40, we employ three extrapolation schemes to extend sample earnings profiles to later ages. First, we use March 2002 Current Population Survey (CPS) data to obtain earnings growth rates up to age 65 . Since the CPS does not contain measures of cognitive ability, it is not possible to extract "low ability" subsamples from the CPS that are comparable to the Perry control group. We use CPS age-by-age growth rates (rather than levels of earnings) of three-year moving average of earnings by race, gender, and educational attainment to extrapolate earnings, thereby avoiding systematic selection effects in levels. ${ }^{30}$ We link the CPS changes to the final Perry earnings. Second, we use the Panel Study of Income Dynamics (PSID) to extrapolate earnings profiles past age-40. In the PSID, there is a word-completion test score from which we can extract a "low ability" subsample in a fashion similar to the way we extract a matched sample from the NLSY79 using AFQT scores. ${ }^{31}$ To extrapolate Perry earnings profiles, we first estimate a random effects model of earnings using lagged earnings, education dummies, age dummies and a constant as regressors. We use the fitted model to extrapolate earnings

\footnotetext{
${ }^{30}$ Belfield et al. (2006) use mean values of CPS earnings in their Perry extrapolations. In doing so, they neglect the point that Perry subjects belong to the bottom of the distribution of ability and the further point that CPS subjects are sampled from a more general population with higher average ability.

${ }^{31}$ For information on how we extract this subsample from PSID, see Web Appendix F.
} 
after age $40 .{ }^{32}$ Third, we also use individual parameters from an estimated Hause (1980) model. For computing rates of return, we obtain complete lifetime earnings profiles from these procedures and compare the results of using alternative approaches to extrapolation on estimated rates of return. ${ }^{33}$ All three methods are conservative in that they impose the same earnings dynamics on treatments and controls. However, in making projections all three methods account for age-40 individual earnings differences between treatments and controls.

The earnings analyzed in Table 3 and Web Appendix G (Tables G.4 and G.5), include all types of fringe benefits listed in Employer Costs for Employee Compensation (ECEC), a Bureau of Labor Statistics (BLS) compensation measure. Even though the share of fringe benefits in total employee compensation varies across industries, due to data limitations, our calculations assume the share to be constant at its economy-wide average regardless of industry. ${ }^{34}$

\footnotetext{
${ }^{32}$ By taking residuals from a regression of earnings on a constant, period dummies and birth year dummies, we can remove fluctuations in earnings due to period-specific and cohort-specific shocks. See Rodgers et al. (1996) for a description of the procedure we use.

${ }^{33}$ For all profiles used here, survival rates by age, gender and education also are incorporated, which are obtained from National Vital Statistics Reports (2004). Belfield et al. (2006) do not account for negative correlation between educational attainment and death rates.

${ }^{34}$ The share of fringe benefit has fluctuated over time with the historical average of about 30 percent. Given the limitations of our data, we apply the economy-wide average share at the corresponding year to each person's earnings assuming all fringe benefits are tax-free.
} 


\subsection{Program Benefits: Criminal Activity}

Crime reduction is a major benefit of the Perry program. ${ }^{35}$ Valuing the effect of crime reduction in terms of costs and benefits is not trivial given the difficulty in assigning reliable monetary values to non-market outcomes. In this sub-section, we improve on the previous studies (for example, Belfield et al. (2006)) by exploring the impact on rates of return and cost-benefit analysis of a variety of assumptions and accounting rules. For each subject, the Perry data provide a full record of arrests, convictions, charges and incarcerations for most of the adolescent and adult years. They are obtained from administrative data sources. ${ }^{36}$ The empirical challenges addressed in this section are twofold: obtaining a complete lifetime profile of criminal activities for each person, and assigning values to that criminal activity. Web Appendix $\mathrm{H}$ presents a comprehensive analysis of the crime data which we summarize in this section.

\footnotetext{
${ }^{35}$ See, for example, Schweinhart et al. (2005), and Heckman, Moon, Pinto, Savelyev, and Yavitz (2009b). Table 2 shows that the effect is mainly due to males. Heckman, Malofeeva, Pinto, and Savelyev (2009a) find evidence that may explain this pattern. Program treatment effects for males mainly operate through enhancing noncognitive or behavioral skills that are very predictive of criminal behavior.

${ }^{36}$ The earliest records cover ages 8-39 and the oldest cover ages 13-44. However, there are some limitations. At the county (Washtenaw) level, arrests, all convictions, incarceration, case numbers, and status are reported. At the state (Michigan) level, arrests are only reported if they lead to convictions. For the 38 Perry subjects spread across the 19 states other than Michigan at the time of the age- 40 interview, only 11 states provided criminal records. No corresponding data are provided for subjects residing abroad.
} 


\subsubsection{Lifetime Crime Profiles}

Even though the arrest records for Perry participants cover most of their adolescent and adult lives, information about criminal activities stops at the time of the age-40 interview. To overcome this problem, we use national crime statistics published in the Uniform Crime Report (UCR), which are collected by the Federal Bureau of Investigation (FBI) from state and local agencies nationwide. The UCR provides arrest rates by gender, race, and age for each year. We apply population rates to estimate missing crime. $^{37}$ See the discussion in Web Appendix H.

\subsubsection{Crime Incidence}

Estimating the impact of the program on crime requires estimating the true level of criminal activity at each age and obtaining reasonable estimates of the social cost of each crime. For a crime of type $c$ at time $t$, the total social cost of that crime $V_{t}^{c}$ can be calculated as a product of the social cost per unit of crime $C_{t}^{c}$ and the incidence $I_{t}^{c}$ :

$$
V_{t}^{c}=C_{t}^{c} \times I_{t}^{c}
$$

We do not directly observe the true incidence level $I_{t}^{c}$. Instead, we only observe each subject's arrest record at age $t$ for crime $c, A_{t}^{c} \cdot{ }^{38}$ If we know

\footnotetext{
${ }^{37}$ We use the year-2002 UCR for this extrapolation.

${ }^{38}$ Given these data limitations, we do not model each individual's criminal behavior so that we are not able to fully account for the individual level dynamics of criminality. We address the heterogeneity of criminal activity across Perry sample members by including
} 
the incidence-to-arrest ratio $I_{t}^{c} / A_{t}^{c}$ from other data sources, we can estimate $V_{t}^{c}$ by multiplying the three terms in the following expression:

$$
V_{t}^{c}=C_{t}^{c} \times \frac{I_{t}^{c}}{A_{t}^{c}} \times A_{t}^{c} .
$$

To obtain the incidence-to-arrest ratio $I_{t}^{c} / A_{t}^{c}$ for each crime of type $c$ at time $t$, we use two national crime datasets: the Uniform Crime Report (UCR) and the National Crime Victimization Survey (NCVS) ${ }^{39}$ The UCR provides comprehensive annual arrest data between 1977 and 2004 for state and local agencies across the U.S. The NCVS is a nationally-representative householdlevel data set on criminal victimization which provides information on levels of unreported crime across the U.S. By combining these two sources, we can calculate the incidence-to-arrest ratio for each crime of type $c$ at time $t$. As noted in the UCR (2002), however, the crime typologies derived from the UCR and those of the NCVS are "not strictly comparable." To overcome this problem, we developed a unified categorization of crimes across the NCVS, UCR, and Perry data sets for felonies (Web Appendix H, Table H.4) and misdemeanors (Web Appendix H, Table H.5). Web Appendix H, Table H.7, shows our estimated incidence-to-arrest ratios for these crimes. To check the

a number of tables and figures in the Web Appendix $\mathrm{H}$ on estimation of the costs of crime and by conducting sensitivity analyses at the aggregate level by including or excluding a group of "hardcore" criminals who repeat crimes.

${ }^{39}$ The Federal Bureau of Investigation website provides annual reports based on UCR (http://www.fbi.gov/ucr/ucr.htm). NCVS are available at Department of Justice website (http://www.ojp.usdoj.gov/bjs/cvict.htm). 
sensitivity of our results to the choice of a particular crime categorization, we use two sets of incidence-to-arrest ratios and compare results. For the first set, we assume that each crime type has a different incidence-to-arrest ratio. These are denoted "Separated" in our tables. For the second set, we use two broad categories, violent vs. property crime. These are denoted by "Property vs. Violent" in our tables. Further, to account for local context, we calculate ratios using UCR/NCVS crime levels that are geographically specific to the Perry program: only crimes committed or arrests made in Metropolitan Sampling Areas of the Midwest. ${ }^{40}$

\subsubsection{Unit Costs of Crime}

Using a simplified version of a decomposition developed in Anderson (1999) and Cohen (2005), we divide crime costs into victim costs and Criminal Justice System costs, which consist of police, court, and correctional costs.

Victim Costs. To obtain total costs from victimization levels, we use unit costs from Cohen (2005). Different types of crime are associated with different victimization unit costs. Some crimes are not associated with any victimization costs. In Web Appendix H, Table H.13, we summarize the unit cost estimates used for different types of crime.

\footnotetext{
${ }^{40}$ For this purpose, the Midwest is defined as Ohio, Michigan, Indiana, Illinois, Wisconsin, Minnesota, Iowa, Missouri, North Dakota, South Dakota, Nebraska, and Kansas. The City of Ypsilanti, where the Perry program was conducted, belongs to the Detroit Metropolitan Sampling Area. For a comparison of these ratios between the local and national levels, see Web Appendix H.3.
} 
Police and Court Costs. Police, court, and other administrative costs are based on Michigan-specific cost estimates per arrest calculated from the UCR and Expenditure and Employment Data for the Criminal Justice System (CJEE) micro datasets. ${ }^{41}$ Since we only observe arrests, and do not know whether and to what extent the courts were involved (for example, whether there was a trial ending in acquittal), we assume that each arrest incurred an average level of all possible police and court costs. This unit cost was applied to all observed arrests (regardless of crime type).

Correctional Costs. Estimating correctional costs in Perry is a more straightforward task, as the data include a full record of incarceration and parole/probation for each subject. To estimate the unit cost of incarceration, we use expenditures on correctional institutions by state and local governments in Michigan divided by the total institution population. To estimate the unit cost of parole/probation, we perform a similar calculation. ${ }^{42}$

\footnotetext{
${ }^{41}$ From Bureau of Justice Statistics (2003), we obtain total expenditures on police and judicial-legal activities by federal, state, and local governments. We divide the expenditures from Michigan state and local governments by the total arrests in this area obtained from UCR. To account for federal agencies' involvement, we add another per-arrest police/court cost which is calculated by dividing the total expenditure of federal government with the total arrests at national level. This calculation is done for years 1982, 1987, 1992, 1997, and 2002. For periods between selected years, we use interpolated values. See Web Appendix $\mathrm{H}$.

${ }^{42}$ Belfield et al. (2006) compute crime-specific criminal-justice system costs. Even though in principle this approach could be more accurate than ours, we do not adopt it in this paper because their data source is questionable and we could not find any other relevant sources. Their unit cost estimates are obtained from a study of the police and courts of Dade County, Florida which has quite different characteristics from Washtenaw County, Michigan where the Perry experiment was conducted. We examine the sensitivity of our estimates to alternate ways to measure costs in Table 5. See Web Appendix H for
} 


\subsubsection{Estimated Social Costs of Crime}

Table 3 summarizes our estimated social costs of crime. Our approach differs from that used by Belfield et al. (2006) in several respects. First, in estimating victimization-to-arrest ratios, police and court costs, and correctional costs, we use local data rather than national figures. Second, we use two different values of the victim cost of murder: an estimate of "the statistical value of life" (\$4.1 million) and an estimate of assault victim cost $(\$ 13,000) .{ }^{43}$ We report separate rates of return for each estimate. Only four murders are observed in the Perry arrest records. ${ }^{44}$ If one uses the statistical value of life as the cost of murder to the victim, a single murder might dominate the calculation of the rate of return. To avoid this problem, Barnett (1996) and Belfield et al. (2006) assign murder the same low cost as assault. We adopt this method as one approach for valuing the social cost of murder, but we also explore an alternative that includes the statistical value of life in murder victimization costs. Contrary to intuition, however, assuming a lower murder cost is not "conservative" in terms of estimating the rate of return because the lone treated male murderer committed his crime at a very early age (21) while the two control male murderers committed their crimes in their late 30s. As a result, assigning a high victimization cost

\footnotetext{
further discussion.

${ }^{43}$ See Cohen (2005) and, for a literature review, see Viscusi and Aldy (2003), who provides a range of $\$ 2-9$ million for the value of a statistical life.

${ }^{44}$ One is committed by a control female, two by control males, and one by a treated male.
} 
to murder decreases the rate of return for males. Given the temporal pattern of murder, we present rate-of-return estimates using both "high" and "low" victim costs for murder (the former includes the statistical value of life, and the latter does not) and compare the results. Third, we assume that there are no victim costs associated with "driving misdemeanors" and "drug-related crimes". Whereas previous studies have assigned non-trivial victim costs to these types of crimes, we consider them to be "victimless". Although such crimes could be the proximal cause of victimizations, such victimizations would be directly associated with other crimes for which we already account. ${ }^{45}$ This approach results in a substantial decrease of crime cost compared to the cost of crime used in previous studies because these specific crimes account for more than 30 percent of all crime reported in the Perry study.

\subsection{Tax Payments}

Taxes are transfers from the taxpayer to the rest of society, and represent benefits to recipients that reduce the welfare of the taxed unless services are received in return. Our analysis considers benefits to recipients, benefits to

\footnotetext{
45 "Driving misdemeanors" include driving without a license; suspended license; driving under the influence of alcohol or drugs; other driving misdemeanors; failure to stop at an accident; improper license plate. "Drug-related crimes" include drug abuse, sale, possession, or trafficking. Belfield et al. (2006) use $\$ 3,538$ to evaluate the cost of "driving misdemeanors" and $\$ 2,620$ for "drug-related crimes" (in year-2006 dollars). Rolnick and Grunewald (2003) do not document how they treat crime. Belfield et al. (2006) compute expected victim costs for these cases, which include, for example, probable risk of death. This practice leads to double counting, and thus to overstating savings in victimization costs due to the Perry program.
} 
the public, and total social benefits (or costs). The latter category nets out transfers but counts costs of collecting and avoiding taxes.

Higher earnings translate into higher absolute amounts of income tax payments (and consumption tax payments) that are beneficial to the general public excluding program participants. Since U.S. individual income tax rates and the corresponding brackets have changed over time, in principle we should apply relevant tax rates according to period, income bracket, and filing status. In addition, most wage earners must pay the employee's share of the Federal Insurance Contribution Act (FICA) tax, such as the Social Security tax and the Medicare tax. In 1978, the employee's marginal and average FICA tax rate for a four-person family at a half of US median income was 6.05 percent of taxable earnings. It gradually increased over time, reaching 7.65 percent in 1990, and has remained at that level ever since. ${ }^{46}$ Here, we simplify the calculation by applying a 15 percent individual tax rate and 7.5 percent FICA tax rate to each subject's taxable earnings in each year. ${ }^{47}$ Belfield, Nores, Barnett, and Schweinhart (2006) use the employer's share of FICA tax in addition to these two components in computing the benefit to the general public, but we do not. A recent consensus among economists is that "employer's share of payroll taxes is passed on to employees in the form

\footnotetext{
${ }^{46}$ See Tax Policy Center (2007).

${ }^{47}$ The "effective" tax rate for the working poor is much higher than this because people lose eligibility for various welfare programs or withdraw benefits as income increases. See Moffitt (2003). Because, in computing the rate of return, we account for the effects of Perry on all kinds of welfare benefits, including in-kind transfers, we apply the baseline tax rates to earnings data alone to avoid double-counting.
} 
of lower wages than would otherwise be paid." 48 Since this tax burden is already incorporated in realized earnings, we do not count it in computing the benefit accrued to the general public while employers who are also among the general public pay some money to the government. Web Appendix J, Tables J.1-J.3, show how individual gross earnings are decomposed into net earnings and tax payments under this assumption.

\subsection{Use of the Welfare System}

Most Perry subjects were significantly disadvantaged and received considerable amounts of financial and non-financial assistance from various welfare programs. Differentials in the use of welfare are another important source of benefit from the Perry program. We distinguish transfers, which may benefit one group in the society at the expense of another, from the costs associated with making such transfers. Only the latter should be counted in computing gains to society as a whole.

We have two types of information on the use of the welfare system: incidence of welfare dependence, and actual welfare payments. Web Appendix I, Table I.1, presents descriptive statistics comparing welfare incidence, the length of welfare spells, and the welfare benefits that are actually received by treatments and controls. One finding is that control females depend on welfare programs more heavily than treatment females before age 27 . That

\footnotetext{
${ }^{48}$ Congressional Budget Office (2007). Anderson and Meyer (2000) present empirical evidence supporting this view.
} 
pattern is reversed at later ages. ${ }^{49}$ For males, the scale of welfare usage is lower, with controls more likely to use welfare at all ages.

Two types of data limitations affect our calculation. One is that we do not have enough information about receipt of various in-kind transfer programs, such as medical, housing, education, and energy assistance, which represent a large portion of total U.S. welfare expenditures. The other is that even for cash assistance programs such as General Assistance (GA), AFDC/TANF, and Unemployment Insurance (UI), we do not have complete lifetime profiles of cash transfers for each individual. Given these limitations, we adopt the following method to estimate full lifetime profiles of welfare receipt.

First, we use the NLSY79 and PSID comparison samples to impute the amount received from various cash assistance and food stamp programs. Prior to age 27, we employ the NLSY79 black "low ability" subsample. Since only the total number of months on welfare programs is known for the Perry sample during this age range, such imputations are unavoidable. We im-

\footnotetext{
${ }^{49}$ Belfield et al. (2006) suggest that "delayed child-rearing and higher educational attainment" among treatment females can explain this phenomenon. However, this pattern is at odds with evidence from the NLSY79 in which greater use of welfare is associated with lower educational attainment. Bertrand, Luttmer, and Mullainathan (2000) show that a person's welfare participation can be affected by behaviors of others in a network. Since the Perry program was conducted in a small town (Ypsilanti, Michigan) and the treated females have known each other from their childhood, they could presumably share and exchange information about welfare programs. This may have made it easier for them to apply and receive benefits. In the NLSY79 which samples randomly from many communities, this effect is unlikely to be at work. If the network effect dominated, the observed contradictory pattern should be interpreted as the composite of treatment effect and network effect. While having a better social network also could be a treatment effect, this distinction would be useful for investigating the external validity of this program.
} 
pute individual monthly welfare receipt for each year using coefficients from NLSY79 individual welfare payments for the corresponding year regressed on gender and education indicators, a dummy variable for teenage pregnancy, number of months in wedlock, employment status, earnings, and the number of biological children. ${ }^{50}$ In this regression, welfare payments include food stamps and all kinds of cash assistance available in the NLSY79 dataset, such as Unemployment Insurance (UI), AFDC/TANF, Social Security, Supplemental Security Income (SSI), and any other cash assistance. For ages 28-40, the Perry records provide both the total number of months on welfare and the cumulative amount of receipts through UI, AFDC, and food stamps. We use the observed amounts for these programs. For other welfare programs, we use a regression-based imputation scheme similar to that used to analyze the data prior to age 27 . The total amount is computed as a sum of these two components. To extrapolate this profile past age 40, we use the PSID dataset, which contains profiles over longer stretches of the life cycle than does the NLSY79. As with the earnings extrapolation, we target the "low-ability" subsample of the PSID dataset. We first estimate a random effects model of welfare receipt using a lagged dependent variable, education dummies, age dummies, and a constant as regressors. We use the fitted model to extrapolate. As with the NLSY79 imputation, the dependent variable in this model includes all cash assistance and food stamps. ${ }^{51}$

\footnotetext{
${ }^{50}$ The exact imputation equation is given in Web Appendix I.

${ }^{51}$ We remove cohort and year effects. See Web Appendices G and I.
} 
Second, to account for in-kind transfers, we employ the Survey of Income and Program Participation (SIPP) data. In SIPP, we calculate the probability of being in specific in-kind transfer programs for a "less-educated" black population born between the years 1956 and 1965, using the year-1984, 1996, and -2004 micro datasets. ${ }^{52}$ We estimate linear probability models for participation in each of a variety of programs using gender and educational attainment variables as predictors. ${ }^{53}$ This calculation is done separately for Medicaid, Medicare, housing assistance, education assistance, energy assistance, public training programs, and other public service programs. We interpolate values for missing data in periods between the years of available data for each SIPP series. Past 2004, we use year-2004 estimates assuming that the current welfare system continues. To convert this probability to monetary values, we use estimates of Moffitt (2003) for real expenditures on the combined federal, state, and local spending for the largest 84 meanstested transfer programs. We adjust upward cash assistance amounts by a product of the probability of participation in each program and the ratio of real expenditures of the in-kind program to that of cash assistance, so that the resulting amount becomes the expected cash value of in-kind receipt. We aggregate across programs to obtain overall totals. Table 3 summarizes our estimated profiles of welfare use.

\footnotetext{
${ }^{52}$ Since SIPP does not contain any kind of ability measure, we use a subsample whose educational attainment is less than or equal to "some college credits without diploma."

${ }^{53}$ We fit the same equation to both treatment and control group members.
} 
For society, each dollar of welfare involves administrative costs. Based on Michigan state data, Belfield, Nores, Barnett, and Schweinhart (2006) estimate a cost to society of 38 cents for every dollar of welfare disbursed. We use this estimate to calculate the cost of welfare programs to society. ${ }^{54}$

\subsection{Other Program Benefits}

Other possibly beneficial effects of the Perry program that are not easily quantified include the psychic cost of education, the utility gain from committing crime, the value of leisure, the value of marital and parental outcomes, the contribution of the program to child care, the value of wealth accumulation, the value of social life, the value of improved health and longevity, and any intergenerational effects of the program. ${ }^{55}$ These benefits are not included in our analysis due to data limitations.

\section{Internal Rates of Return and Benefit-To-Cost Ratios}

In this section, we calculate internal rates of return and benefit-to-cost ratios for the Perry program under various assumptions and estimation methods. The internal rate of return (IRR) compares alternative investment

\footnotetext{
${ }^{54}$ This cost consists of two components: the cost of administering welfare disbursement and the cost accrued due to overpayments and payments to ineligible families.

${ }^{55}$ In this study, we do not include the child care cost that parents of program subjects would have paid without this program. Thus, we likely underestimate the true benefits. Belfield, Nores, Barnett, and Schweinhart (2006) count child care for participants as a benefit, even for women who do not work, and hence they inflate the benefits of the Perry program. The effect of the program on longevity is accounted for to some degree because we adjust all profiles used in this study for survival rates by age, gender and educational attainments.
} 


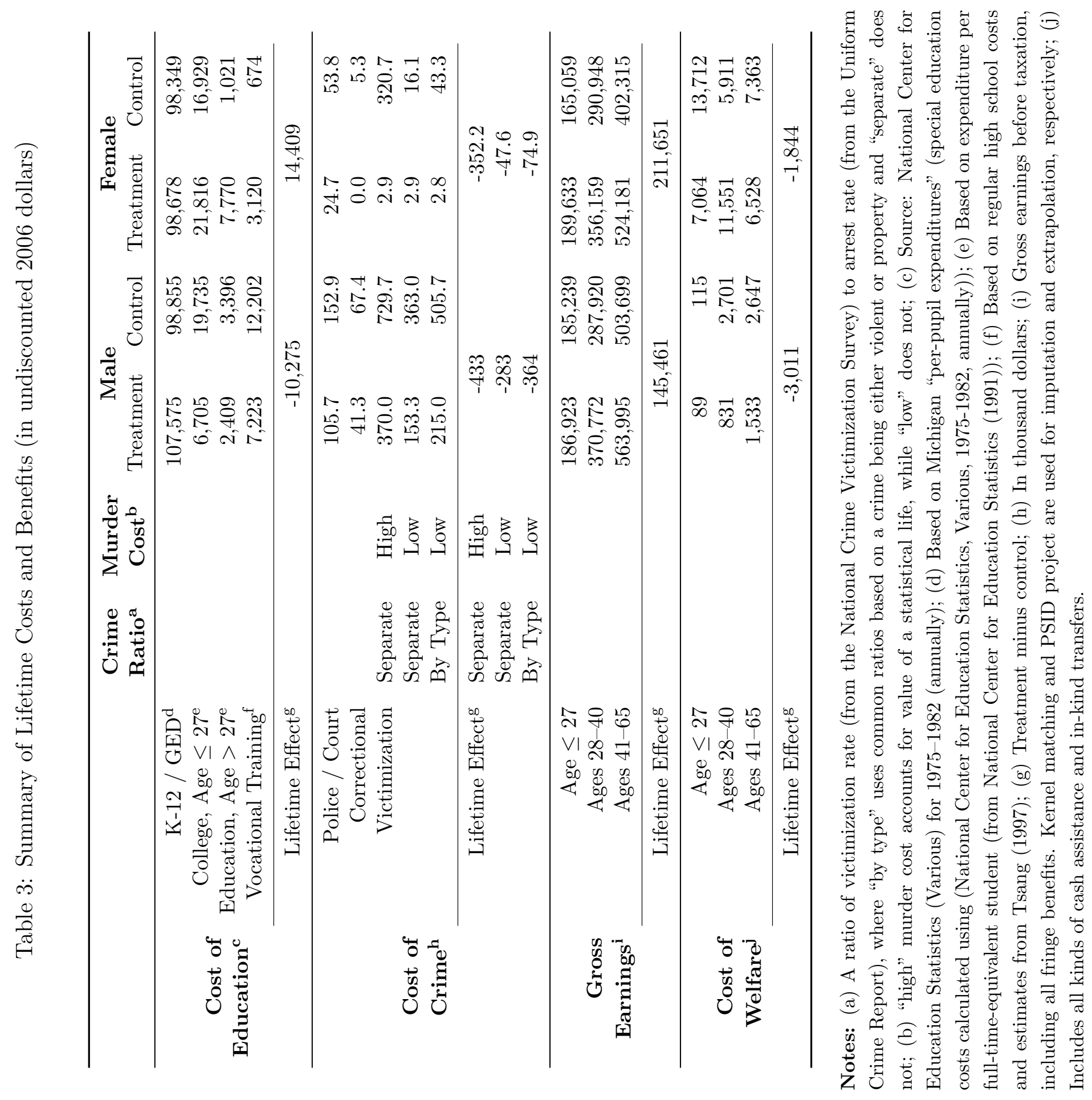


projects in a common metric. For each gender and treatment group, we construct average life cycle benefit and cost profiles and then compute IRRs. We also compute standard errors for all of the estimated IRRs and benefit-tocost ratios. The computation of standard errors is constructed in three steps. In the first step, we use the bootstrap to simultaneously draw samples from Perry, the NLSY79, and the PSID. ${ }^{56}$ For each replication, we re-estimate all parameters that are used to impute missing values, and re-compute all components used in the construction of lifetime profiles. Notice that in this process, all components whose computations do not depend on the comparison group data also are re-computed (e.g., social cost of crime, educational expenditure, etc.) because the replicated sample consists of randomly drawn Perry participants. In the second step, we adjust all imputed values for prediction errors on the bootstrapped sample by plugging in an error term which is randomly drawn from comparison group data by a Monte Carlo resampling procedure. Combining these two steps allows us to account for both estimation errors and prediction errors. Finally we compute point estimates of IRRs for each replication to obtain bootstrap standard errors. Web Appendix $\mathrm{K}$ describes in greater detail the procedure used to compute our standard errors.

Table 4 and Web Appendix J show estimated IRR's computed using various methods for estimating earnings profiles and crime costs and under var-

\footnotetext{
${ }^{56}$ For procedures that use different nonexperimental samples, we conduct the same analyis.
} 


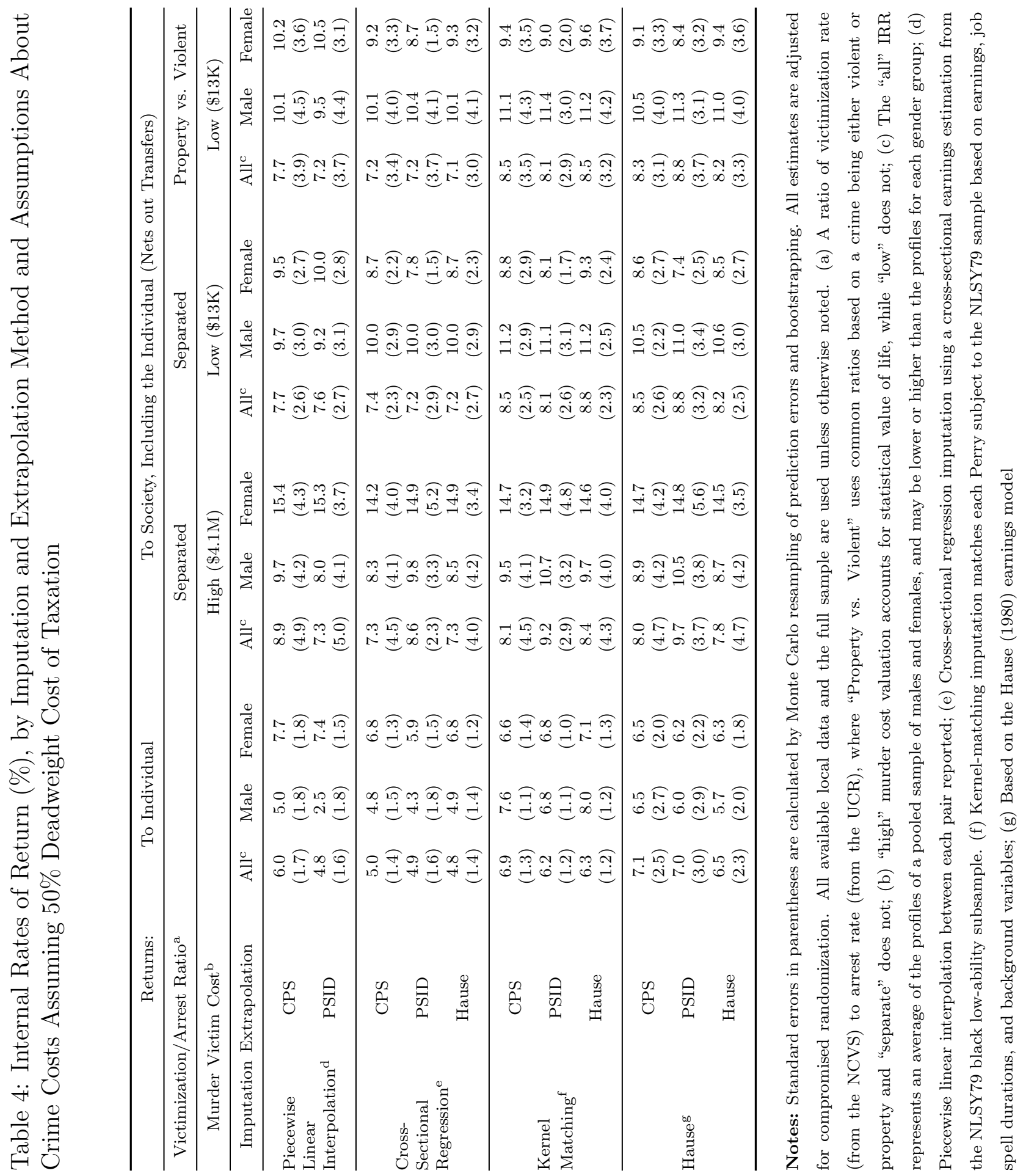


ious assumptions about the deadweight cost of taxation. Numbers in parentheses below each estimate are the associated standard errors. We first use the victim cost associated with a murder as $\$ 4.1$ million, which includes the statistical value of life (Column labeled "High"). We also provide calculations setting the victim cost of murder to that of assault, which is about $\$ 13,000$, to avoid the problem that a single murder might dominate the evaluation (final two sets of columns). To gauge the sensitivity of estimated returns to the way crimes are categorized, we first assume that crimes are separated and compute victimization ratios separately for each crime (columns labeled "Separated"). We then aggregate crimes into two categories: property and violent crimes, and compute victimization ratios within each category. Average costs of crime are computed for each category. The estimates reported in these tables account for the deadweight costs of taxation: dollars of welfare loss per tax dollar. Since different studies suggest various estimates of the size of the deadweight cost of taxation, in this paper we show results under various assumptions for the size of deadweight loss associated with $\$ 1$ of taxation: 0, 50, and 100 percent. ${ }^{57}$ There are many components of the calculation that are affected by this consideration: initial program cost, school expenditure paid by the general public, welfare receipt and the overhead cost of welfare paid by the general public, and all kinds of criminal justice

\footnotetext{
${ }^{57}$ See Browning (1987), Heckman and Smith (1998), Heckman et al. (1999), and Feldstein (1999) for discussion of estimates of deadweight costs.
} 
system costs such as police, court, and correctional costs. ${ }^{58}$ The Perry program incurs the deadweight costs associated with initial funding but saves the deadweight costs associated with taxes used to fund transfer recipients. Table 1 provides a comparison of results across different assumptions of the deadweight costs and the real discount rate for the selected earnings imputation and extrapolation method. Table 4 presents results across different earnings imputation and extrapolation methods using our preferred estimate of $50 \%$ for the deadweight cost. ${ }^{59}$ Estimates based on kernel matching imputation and PSID projection of missing earnings are reported in Table 1. Table 4 shows that our estimates are robust to the choice of alternative extrapolation/interpolation procedures. ${ }^{60} \mathrm{~A}$ complete set of our results can be found in Web Appendix J.

Heckman, Moon, Pinto, Savelyev, and Yavitz (2009b) document that the randomization protocol implemented in the Perry program is somewhat prob-

\footnotetext{
${ }^{58}$ We do not apply this adjustment to income tax paid by Perry subjects to avoid double counting. Observed earnings are already adjusted for taxes. See the discussion in Web Appendix J.

${ }^{59}$ In principle, since different types of taxes are levied by different jurisdictions that create different deadweight losses, we should account for this feature of the welfare system. In practice, this is not possible. Web Appendix J, Tables J.1-J.3, take the reader through the calculation underlying three of the cases reported in this table.

${ }^{60}$ The kernel matching procedure imposes the fewest functional form assumptions on the earnings equations on the Perry-NLSY79 matched data, and is more data-sensitive than crude interpolation schemes. The PSID projection imposes an autogressive earnings function with freely specified covariates on the Perry-PSID matched data, which is the least functionally form dependent. At the same time it enables us to link post-age- 40 earnings with the observed earnings at 40 and respects differences in unobservables between treatments and controls. For details, see Appendix G.
} 
lematic. ${ }^{61}$ Post-randomization reassignments were made to promote compliance with the program. This and other modifications to simple random assignment created an imbalance between treatment and control group in family background such as father's presence at home, an index of socioeconomic status (SES), and mother's employment status at program entry. ${ }^{62}$ This imbalance could induce a spurious relationship between outcomes and treatment assignments, which violates the assumption of independence that is the core concept of a randomized experiment. To produce valid IRRs and standard errors, analysts of the Perry data should take into account the corruption of the randomization protocol used to evaluate the Perry program and examine its effects on estimated rates of return. One way to control for potential biases is to condition all lifetime cost and benefit streams on the variables that determine reassignment. By adjusting cost and benefit streams for these variables, corruption-adjusted IRRs and the associated standard errors can be computed. ${ }^{63}$ All results presented in Table 4 are ad-

\footnotetext{
${ }^{61}$ For details on the randomization protocol, see Weikart et al. (1978) and Heckman, Moon, Pinto, Savelyev, and Yavitz (2009b). The latter paper analyzes program treatment effects accounting for the corrupted randomization. For further discussion of the randomization procedure, see Web Appendix L.

${ }^{62}$ The fraction of children with working mothers at study entry is much higher in the control group (31\%) than in the treatment group (9\%). This trend continues to hold when males and females are viewed separately. In contrast, treatment females had a greater fraction of fathers present at study entry than control females (68\% vs. $42 \%)$, while treatment males had a smaller fraction of fathers present than control males $(45 \%$ vs. $56 \%$ ).

${ }^{63}$ We use the Freedman-Lane procedure discussed in Heckman, Moon, Pinto, Savelyev, and Yavitz (2009b). They show that the results from this procedure agree with the results obtained from other parametric and semiparametric estimation procedures.
} 
justed for compromised randomization. Appendix L compares estimates with and without this adjustment. The adjustment does not greatly change the estimated IRR although it affects the strength of individual level treatment effects (Heckman, Moon, Pinto, Savelyev, and Yavitz, 2009b). ${ }^{64}$

The estimated rates of return reported in Table 4 are comparable across different imputation and extrapolation schemes. Kernel matching imputation tends to produce slightly higher estimates. Alternative extrapolation methods have a more modest effect on estimated rates of return. ${ }^{65}$ Alternative assumptions about the victim cost of murder — whether to include the statistical value of life - affect the estimated rates of return in a counterintuitive fashion. Assigning a high number to the value of a life lowers the estimated rate of return because the one murder committed by a treatment group male occurs earlier than the two committed by males in the control group. ${ }^{66}$ Although estimated costs are sensitive to assumptions about the victimization cost associated with murder, they are not very sensitive to the crime categorization method. Adjusting for deadweight losses of taxes lowers the rate of return to the program. Our estimates of the overall rate of return hover in the range of 7-10 percent, and are statistically significantly different

\footnotetext{
${ }^{64}$ However, notice that the effects on the estimated rates of return are not always in the same direction.

${ }^{65}$ The profiles labeled as "all" pool the data regardless of gender. The IRR from pooled samples can be higher or lower than the IRR for each separate gender subsample.

${ }^{66}$ Thus, when Belfield et al. (2006) assign a low value to murder victimization, they are actually presenting an upward-biased estimate.
} 
from zero in most cases. ${ }^{67}$

Table 5 presents some sensitivity analyses. First, it demonstrates how IRRs change when we exclude outliers from our computation. We consider two types of outliers: subjects who attain more than a 4-year college degree and a group of "hard-core" criminal offenders. In the Perry dataset, we observe 2 subjects who acquired master's degrees: 1 control male and 1 treatment female. Compared to the "full sample" result, excluding these subjects has only modest effects on the estimated IRRs. To exclude the "hard-core" criminals, we use "the total number of lifetime charges" through age 40 including juvenile crimes. We exclude the top 5 percent (six persons) of hard-core offenders from the full sample and recalculate the IRRs. ${ }^{68}$ Eliminating these offenders increases the estimated social IRRs obtained from the pooled sample, and strengthens the precision of the estimates.

Table 5 also compares our estimates with two other sets of IRRs: one based on national figures in all computations and the other on crime-specific criminal justice system (CJS) costs used in Belfield et al. (2006). Accounting for local costs instead of relying on national figures increases estimated IRRs. The signs and magnitude of the effect of using local costs differs by cost component. As noted in Section 3, schooling expenditures for K-12 ed-

\footnotetext{
${ }^{67}$ Tables J.4 and J.5 in Web Appendix J present the estimates for other assumptions about deadweight loss.

${ }^{68}$ Web Appendix H, Table H.12, identifies these individuals. This group consists of 3 control males and 3 treatment males. This small group commits about 25 percent of all charges and 27 percent of all felony charges associated with non-zero victim cost.
} 


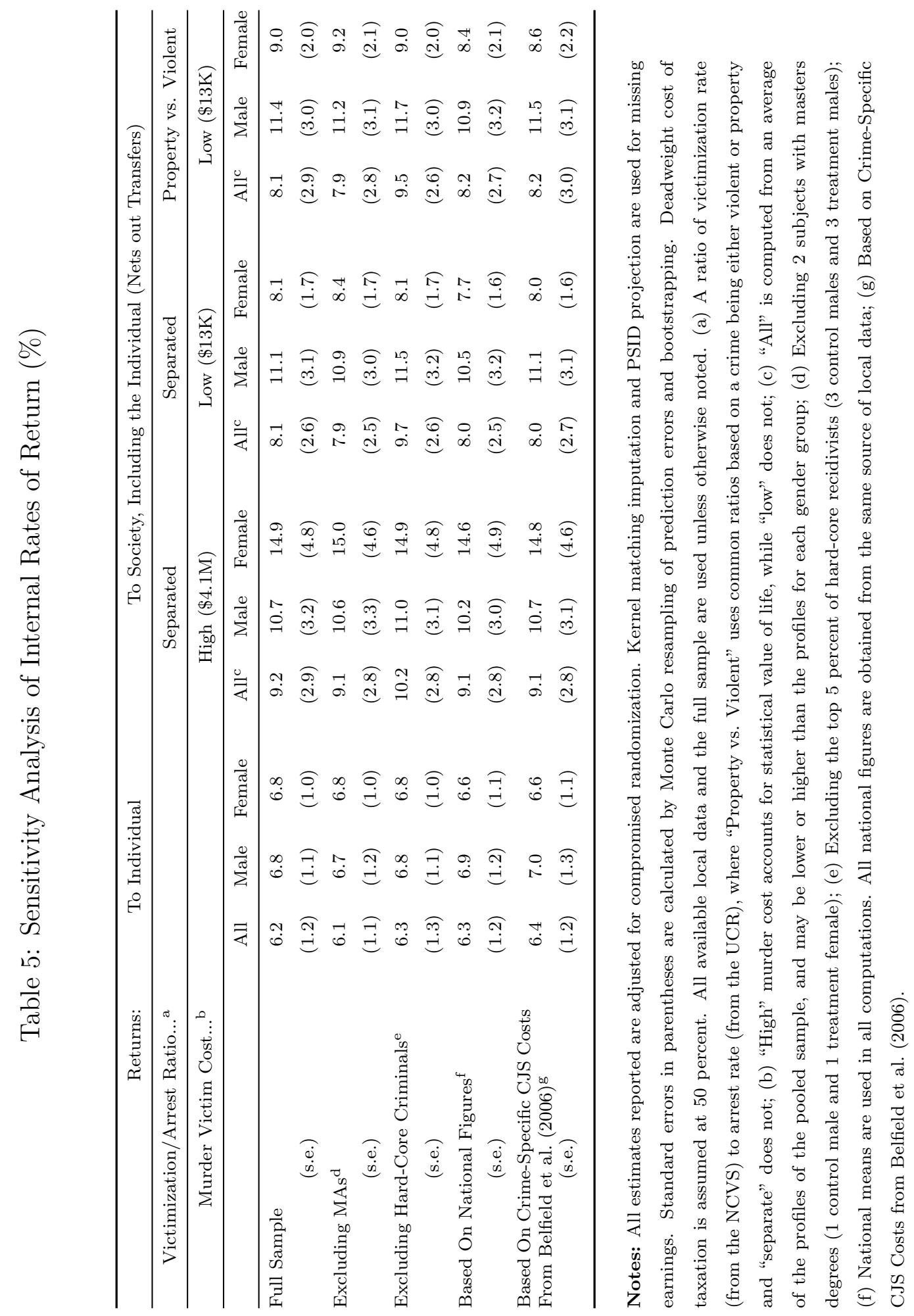


ucation in Michigan are slightly higher than the corresponding figures at the national level, although accounting for this has only modest effects on the estimated IRRs. The modest effect arises because total education expenditure is not substantially different between the control and the treatment group after accounting for grade retention, special education, and years in regular schooling. Using local crime costs increases the estimated IRR and increases the precision of the estimates. No clear pattern emerges from using local versus national victimization-to-arrest ratios. However, criminal justice system costs for Michigan are unambiguously higher than the corresponding national costs and accounting for these raises the estimated rate of return. Using the crime-specific CJS costs employed by Belfield et al. (2006) has mixed effects on the estimated IRR depending on the victimization-to-arrest ratio used. As noted in Section 3, their estimated costs of the criminal justice system are based on data collected from a specific local area whose characteristics are quite different from the region where the Perry program was conducted.

\subsection{Benefit-To-Cost Ratios}

As noted in Hirshleifer (1970), use of the IRR to evaluate programs is potentially problematic. ${ }^{69}$ For this reason, it is useful to consider benefit-to-

\footnotetext{
${ }^{69}$ The internal rate of return is the solution $\rho$ of a polynomial equation $\sum_{t=1}^{T} \frac{Y_{t}^{T r}-Y_{t}^{C t l}}{(1+\rho)^{t}}-$ $\bar{C}=0$, where $Y_{t}^{T r}$ and $Y_{t}^{C t l}$ denote lifetime net benefit streams at time $t$ for treatment and control group, respectively, and $\bar{C}$ is the initial program cost. Given the high order of this equation $(\mathrm{T}=65-3=62)$, there may be multiple real solutions and some solutions may be complex. Fortunately, however, a unique positive real root $\rho^{*}$ is found for all of the combination of methodologies and assumptions examined in this paper. While we obtain
} 
cost ratios using different discount rates. Table 1 and Tables J.6-J.9 in Web Appendix J present the benefit-to-cost ratios and the associated standard errors under different assumptions about the discount rate, the deadweight cost of taxation, the method of extrapolation and the method of interpolation. Table L.1 shows the benefit-to-cost ratios adjusted for compromised randomization. The effects of the adjustment are modest. For typical discount rates (3-5 percent) that are below the internal rates of return presented in Table 1 , we estimate substantial benefit-to-cost ratios. ${ }^{70}$ The benefit-to-cost ratios generally support the rate of return analysis.

\subsection{Crime versus Other Outcomes}

Table 6 decomposes the benefit-to-cost ratio reported in Table 1 (reproduced in the first three columns of the table) into components due to crime reduction and other components. The percentage contributions of "crime" and "other" components are given in the third row in each segment of the Table 6. For both males and females, the contribution of crime to the overall benefit-cost ratio is substantial when a high value of victim's life is assumed. The contribution declines when lower values are placed on victim lives.

For females, both the rate of return and the benefit-cost ratio are larger

a unique positive real IRR, it is still problematic whether IRR or Benefit-to-Cost ratio can serve as a "correct" criterion for a policy decision comparing two mutually exclusive projects since the project with the higher internal rate of return can have a lower present value than a rival project. See Hirshleifer (1970, p. 76-77). Carneiro and Heckman (2003) discuss the limits of the IRR in the context of evaluating early childhood programs.

${ }^{70}$ The appropriate social discount rate is a hotly debated topic. Some have argued for a zero or negative social discount rate (Dasgupta, Mäler, and Barrett, 2000). 
the higher the value placed on a murder victim's life. For males, the rate of return decreases when a higher value is placed on life. The benefit-cost ratio increases. This pattern is explained by the time pattern of murders among male treatments and controls. The one male treatment murder occurs at an early age. The two male control murders occur at later ages. At a zero rate of discount, the timing of the murders does not matter. Because of the high internal rates of return that we estimate, the timing matters. At a sufficiently high discount rate, the male benefit-to-cost ratios decline as the value of life increases.

\subsection{Age 40 Analysis}

Table 7 presents a more conservative version of our preferred analysis (kernel matching for imputation and PSID extrapolation with a $50 \%$ deadweight loss). Instead of computing the rate of return and benefit-cost ratios through age 65 , we compute rate of returns and benefit-cost ratios only through age 40, assuming that benefits stop after that age. This eliminates the need to extrapolate past age 40, and thus eliminates one source of model uncertainty. We compare the estimates from the third row of Table 4 with the estimates that assume that benefits stop at age 40 .

Unsurprisingly, rates of return and benefit-cost levels fall somewhat, but in most cases they remain precisely determined. Even under this very conservative assumption, the rate of return is substantial, precisely estimated, and above the historical yield on equity. 

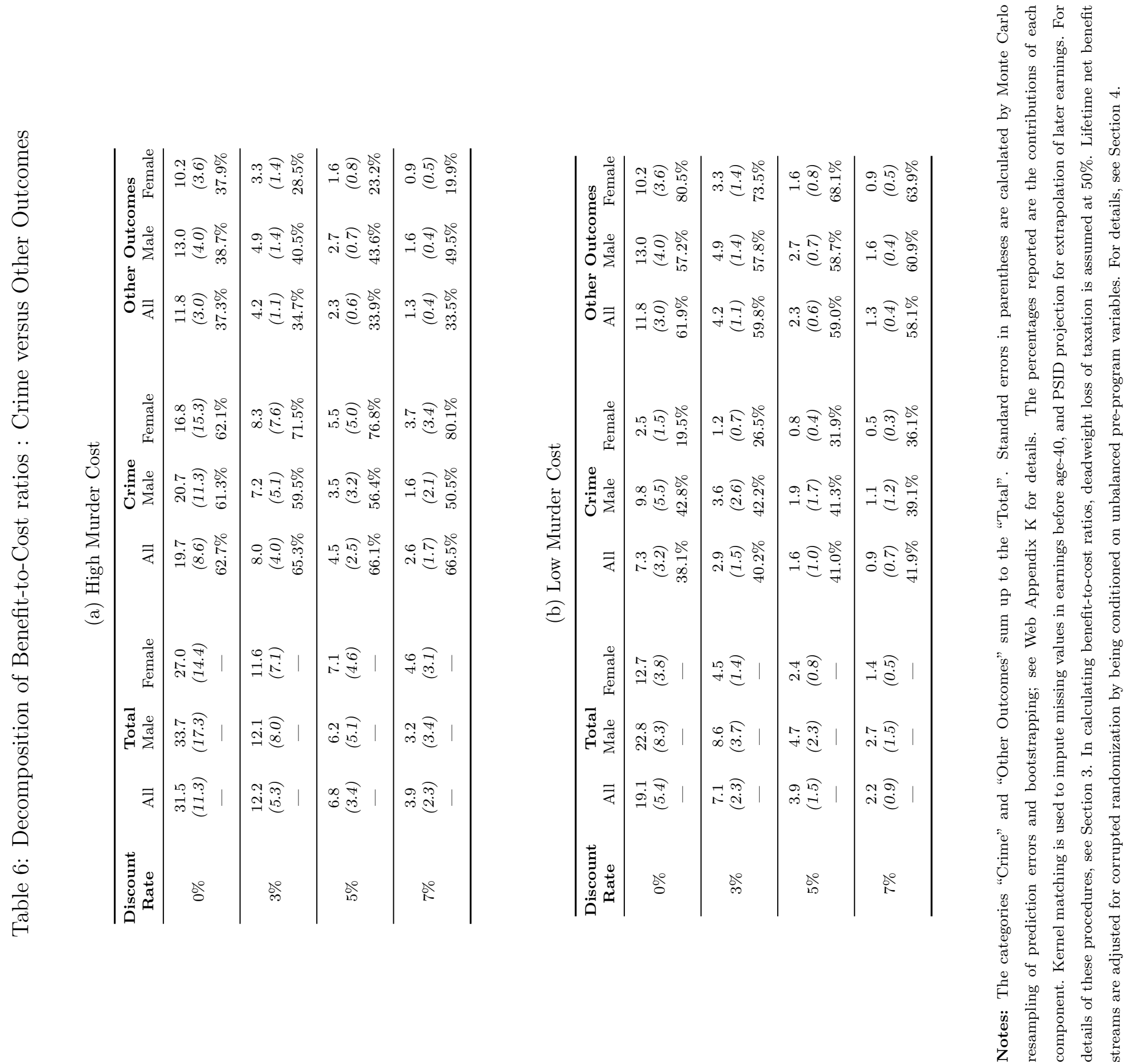


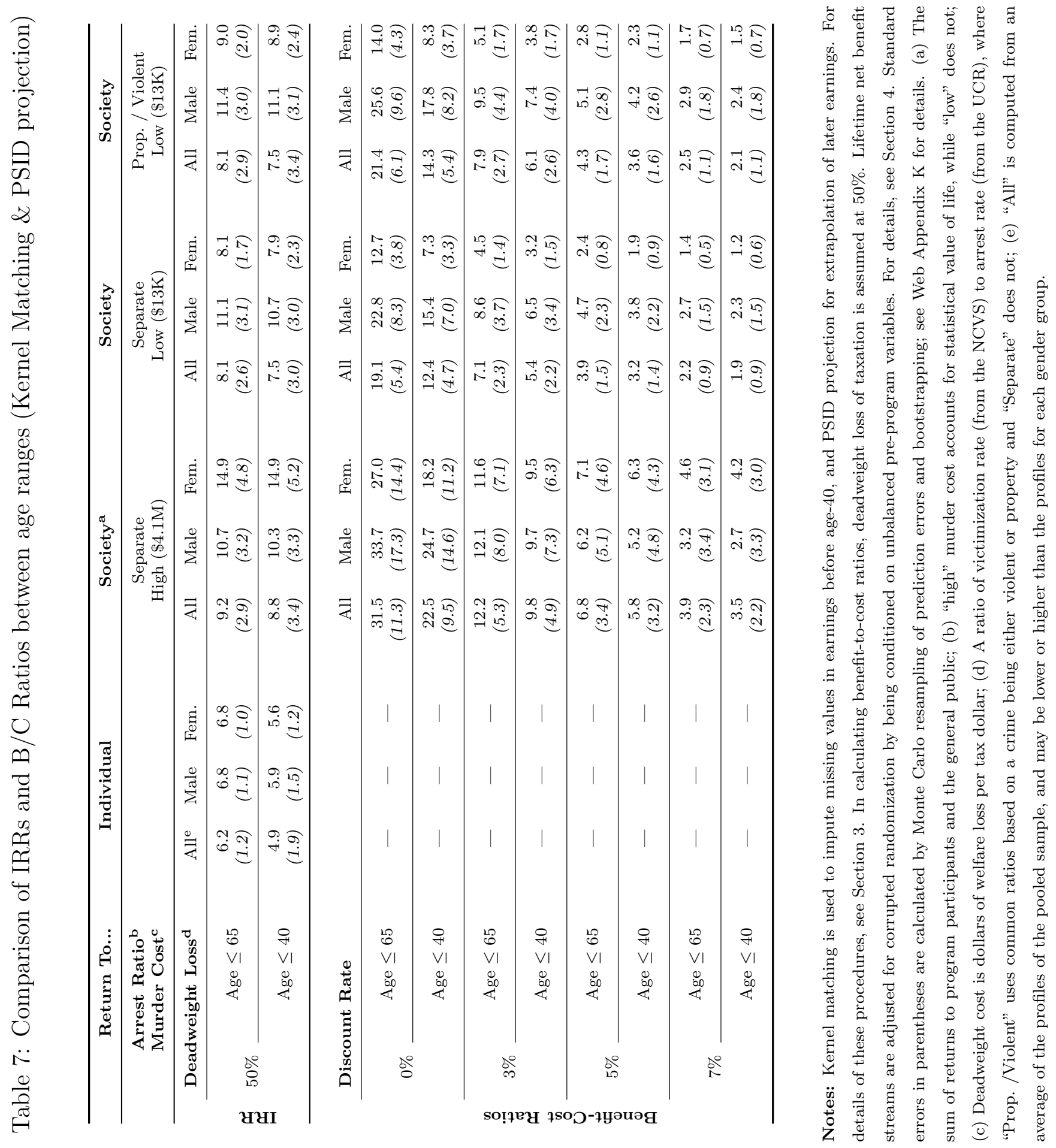




\subsection{Comparisons with Previous Studies}

Internal rates of return for the Perry program have been reported in two previous studies by Rolnick and Grunewald (2003) and Belfield, Nores, Barnett, and Schweinhart (2006). Our estimates of the IRR are lower than those reported in previous studies. While a number of factors produce this effect, the dominant source of the difference between our estimates and the previous estimates is in our treatment of crime and its social costs. In particular, as noted in Section 3, treatment of the social cost of some "victimless" crimes plays a crucial role.

Table 8 compares the estimates reported in previous studies with those reported in this paper. While we employ a variety of methods to estimate lifetime costs and benefits, here we present estimates from a method that is similar to the one used in previous studies: linear interpolation and CPSbased extrapolation for missing earnings along with crimes separated by type and a low murder cost $(\$ 13,000)$ assumption. We present two sets of results: one with no deadweight loss, and the other with a 50 percent deadweight loss, which we prefer. Each set is reported adjusting and not adjusting for the compromised randomization of the program - a feature never considered in previous studies of the Perry program. As previously noted for both the benefit-cost ratio, and the rate of return, adjustment has fairly modest consequences. In addition, no previous study accounts for the deadweight cost of taxation. Compared to the two previous studies, our estimated program benefits are smaller for education and crime, and larger for earnings 
and welfare costs.

The difference in education cost estimates is mainly caused by our treatment of vocational training. As shown in Web Appendix J, Table J.1, the costs of college education and vocational training differ between control and the treatment groups, while the K-12 education costs do not. Previous studies do not account for costs of vocational training.

Our estimated earning differentials are larger for males and smaller for females compared to those reported in previous studies. While our imputation method for missing earnings before age 40 is similar in many respects to the method used in previous studies, our extrapolation method for ages after 40 is different. We account for the fact that Perry subjects are at the bottom of the distribution of ability by using CPS age-by-age growth rates (rather than levels of earnings) to make extrapolations by race, gender and educational attainment. Previous studies neglect this aspect of the Perry sample and use national means of CPS earnings to project missing earnings, inflating the level of earnings for both treatments and controls.

Another major difference between our study and previous ones lies in our treatment of the social cost of crime. Our estimated effect of crime reduction is much smaller than that reported in two previous studies. We assume no victim costs are associated with "driving misdemeanors" and "drug-related crimes". Previous studies assign non-trivial victim costs to these crimes. We consider these crimes as "victimless." Even though these crimes may be associated with other crimes which may generate victims, such crimes 
would be recorded separately in the Perry crime record. This more careful accounting for crime results in a substantial decrease of the estimated cost of crime because victimless crimes account for more than 30 percent of all crime incidence reported in the Perry crime record.

\section{Conclusion}

This paper estimates the rate of return and the benefit-cost ratio for the Perry Preschool Program, accounting for locally determined costs, missing data, the deadweight costs of taxation, and the value of non-market benefits and costs. It improves on previous estimates by accounting for corruption in the randomization protocol, by developing standard errors for these estimates and by exploring the sensitivity of estimates to alternative assumptions about missing data and the value of non-market benefits. Our estimates are robust to a variety of alternative assumptions about interpolation, extrapolation, and deadweight losses. In most cases, they are statistically significantly different from zero. This is true for both males and females. ${ }^{71}$ In general, the estimated rates of return are above the historical return to equity of about 5.8 percent but below previous estimates reported in the literature. Table 1 summarizes our estimates of the rate of return for selected methodologies. Our benefit-to-cost ratio estimates support the rate of return analysis. Ben-

\footnotetext{
${ }^{71} \mathrm{~A}$ recent paper by Anderson (2008) claims to find no effect for the Perry program for males. He focuses on only a few arbitrarily weighted outcomes and does not compute rates of return or benefit-cost ratios.
} 


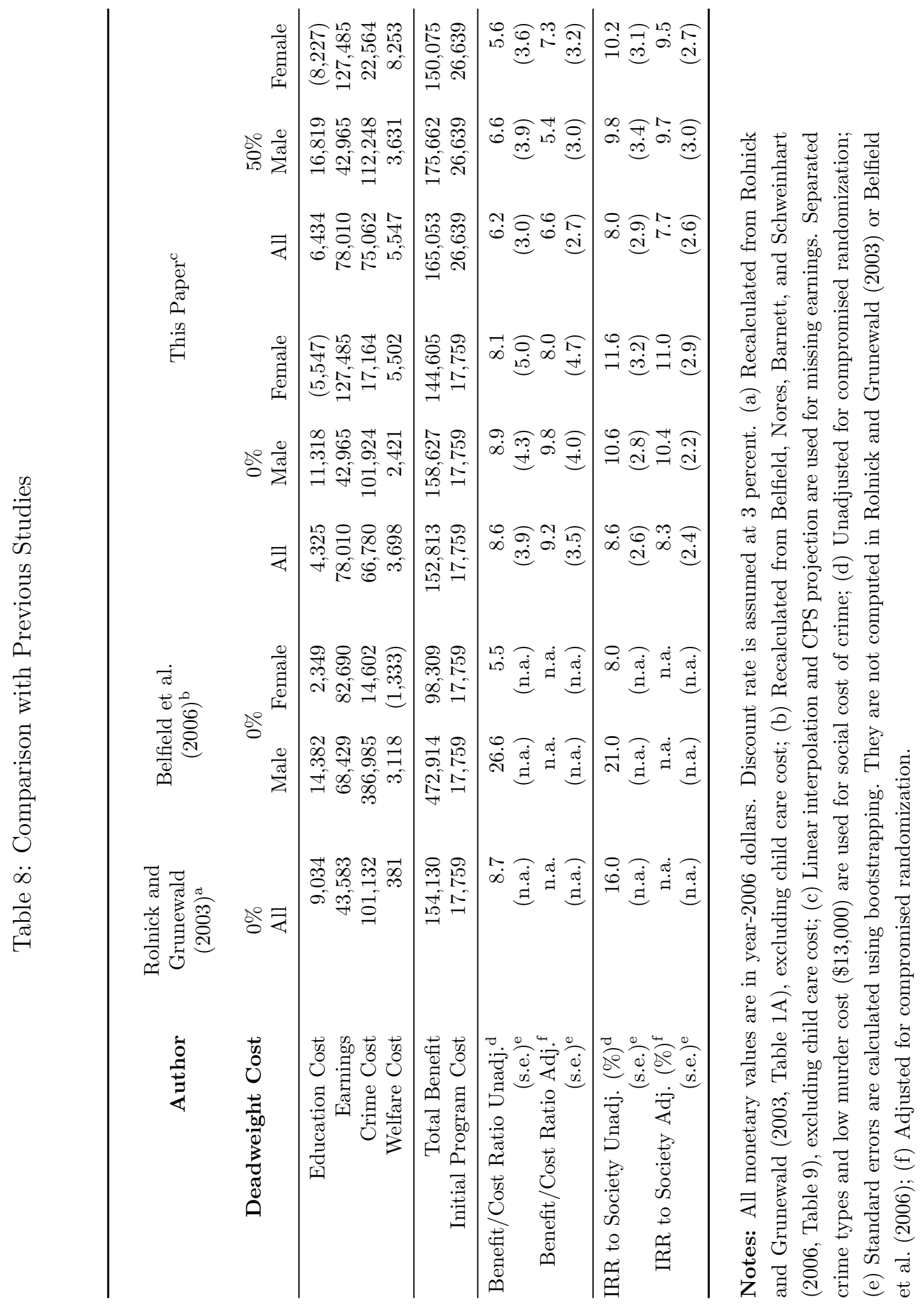


efits on health and the well-being of future generations are not estimated due to data limitations. All things considered, our analysis likely provides a lower-bound on the true rate of return to the Perry Preschool Program. ${ }^{72}$

\section{Acknowledgements}

We are grateful to Lena Malofeeva and Larry Schweinhart of the High/Scope Foundation for their comments and their continued support of our ongoing collaboration. We are grateful to the editor, Dennis Epple, and two anonymous referees for their comments and to Steve Durlauf, Jeff Grogger and participants at the Public Policy and Economics seminar at the Harris School, University of Chicago, March, 2009. This research was supported by the Committee for Economic Development by a grant from the Pew Charitable Trusts and the Partnership for America's Economic Success (PAES); the JB \& MK Pritzker Family Foundation; Susan Thompson Buffett Foundation; and NICHD (R01HD043411). The views expressed in this presentation are those of the authors and not necessarily those of the funders listed here. Supplementary materials may be retrieved from http://jenni.uchicago.edu/Perry/cba/.

\footnotetext{
${ }^{72}$ Our analysis answers many of the objections raised by Nagin (2001) against previous cost-benefit studies of the returns to early interventions. We consider costs and benefits to society, rather than governments or individuals alone. However, due to data limitations, we do not value the psychic benefits of crime reduction to society at large apart from the reduction in victimization costs.
} 


\section{References}

Anderson, D. A., October 1999. The aggregate burden of crime. Journal of Law and Economics 42 (2), 611-642.

Anderson, M., December 2008. Multiple inference and gender differences in the effects of early intervention: A reevaluation of the Abecedarian, Perry Preschool and early training projects. Journal of the American Statistical Association 103 (484), 1481-1495.

Anderson, P. M., Meyer, B. D., October 2000. The effects of the unemployment insurance payroll tax on wages, employment, claims and denials. Journal of Public Economics 78 (1-2), 81-106.

Bajaj, V., Labaton, S., February 1 2009. Big risks for U.S. in trying to value bad bank assets. New York Times Business/Economy.

URL http://www.nytimes.com/2009/02/02/business/economy/ 02value.html (accessed2/4/2009)

Barnett, W. S., 1996. Lives in the Balance: Age 27 Benefit-Cost Analysis of the High/Scope Perry Preschool Program. High/Scope Press, Ypsilanti, MI.

Barnett, W. S., Masse, L. N., February 2007. Comparative benefitcost analysis of the Abecedarian program and its policy implications. Economics of Education Review 26 (1), 113-125. 
Belfield, C. R., Nores, M., Barnett, W. S., Schweinhart, L., 2006. The High/Scope Perry Preschool program: Cost-benefit analysis using data from the age-40 followup. Journal of Human Resources 41 (1), 162-190.

Bertrand, M., Luttmer, E. F. P., Mullainathan, S., August 2000. Network effects and welfare cultures. Quarterly Journal of Economics 115 (3), 1019 1055.

Browning, E. K., March 1987. On the marginal welfare cost of taxation. American Economic Review 77 (1), 11-23.

Carneiro, P., Heckman, J. J., 2003. Human capital policy. In: Heckman, J. J., Krueger, A. B., Friedman, B. M. (Eds.), Inequality in America: What Role for Human Capital Policies? MIT Press, Cambridge, MA, pp. 77-239.

Chambers, J. G., Parrish, T. B., Harr, J. J., 2004. What are we spending on social education services in the united states, 1999-2000? Report 1, Special Education Expenditure Project (SEEP). Center for Special Education Finance, United States Department of Education, Office of Special Education Programs, Washington, DC.

Cohen, M. A., 2005. The Costs of Crime and Justice. Routledge, New York. Congressional Budget Office, 2007. Historical Effective Federal Tax Rates: 1979 to 2005. Congressional Budget Office, Washington, DC.

Dasgupta, P., Mäler, K.-G., Barrett, S., 2000. Intergenerational equity, social discount rates and global warming, unpublished manuscript, Department 
of Economics, University of Cambridge. Revised version of the paper with the same title that was published in Discounting and Intergenerational Equity, (Washington, DC: Resources for the Future, 1999).

DeLong, J., Magin, K., Winter 2009. The U.S. equity return premium: Past, present and future. Journal of Economic Perspectives 23 (1), 193208.

Dillon, S., December 17 2008. Obama pledge stirs hope in early education. New York Times US Politics, early edition.

URL http://www.nytimes.com/2009/02/02/business/economy/ 02value.html (accessed2/4/2009)

Fanton, J., 2008. Philanthropy, benefit-cost analysis, and public policy, remarks by Jonathan F. Fanton at the 2008 Benefit-Cost Analysis Conference, Washington D.C., June 25, 2008.

URL http://www.macfound.org/site/apps/nlnet/content3.aspx?c= $1 \mathrm{kLXJ} 8 \mathrm{MQKrH} \& \mathrm{~b}=4255617 \& \mathrm{ct}=5597397$

Federal Bureau of Investigation, 2002. Crime in the United States. Department of Justice, Federal Bureau of Investigation, Washington, DC, database, 1995-2001.

URL http://www.fbi.gov/ucr/02cius.htm

Feldstein, M., November 1999. Tax avoidance and the deadweight loss of the income tax. Review of Economics and Statistics 81 (4), 674-680. 
Garces, E., Thomas, D., Currie, J., September 2002. Longer-term effects of Head Start. American Economic Review 92 (4), 999-1012.

Goldin, C., Katz, L. F., 2008. The Race between Education and Technology. Belknap Press of Harvard University Press, Cambridge, MA.

Hanushek, E., Lindseth, A. A., 2009. Schoolhouses, Courthouses, and Statehouses: Solving the Funding-Achievement Puzzle in America's Public Schools. Princeton University Press, Princeton, NJ.

Hause, J. C., May 1980. The fine structure of earnings and the on-the-job training hypothesis. Econometrica 48 (4), 1013-1029.

Heckman, J. J., 2005. Invited comments. In: Schweinhart, L. J., Montie, J., Xiang, Z., Barnett, W. S., Belfield, C. R., Nores, M. (Eds.), Lifetime Effects: The High/Scope Perry Preschool Study Through Age 40. High/Scope Press, Ypsilanti, MI, pp. 229-233, Monographs of the High/Scope Educational Research Foundation, 14.

Heckman, J. J., LaFontaine, P. A., 2008. The GED and the Problem of Noncognitive Skills in America. University of Chicago Press, Chicago, forthcoming.

Heckman, J. J., LaLonde, R. J., Smith, J. A., 1999. The economics and econometrics of active labor market programs. In: Ashenfelter, O., Card, D. (Eds.), Handbook of Labor Economics. Vol. 3A. North-Holland, New York, Ch. 31, pp. 1865-2097. 
Heckman, J. J., Malofeeva, L., Pinto, R., Savelyev, P. A., 2009a. The effect of the Perry Preschool Program on the cognitive and non-cognitive skills of its participants, unpublished manuscript, University of Chicago, Department of Economics.

Heckman, J. J., Moon, S. H., Pinto, R., Savelyev, P. A., Yavitz, A. Q., 2009b. A Reanalysis of the HighScope Perry Preschool Program, unpublished manuscript, University of Chicago, Department of Economics. First draft, September, 2006.

Heckman, J. J., Smith, J. A., 1998. Evaluating the welfare state. In: Strom, S. (Ed.), Econometrics and Economic Theory in the Twentieth Century: The Ragnar Frisch Centennial Symposium. Cambridge University Press, New York, pp. 241-318.

Herrnstein, R. J., Murray, C. A., 1994. The Bell Curve: Intelligence and Class Structure in American Life. Free Press, New York.

Hirshleifer, J., 1970. Investment, Interest, and Capital. Prentice-Hall, Englewood Cliffs, NJ.

Karoly, L. A., Kilburn, M. R., Cannon, J. S., 2005. Early Childhood Interventions: Proven Results, Future Promise. RAND, Santa Monica, CA.

MaCurdy, T. E., 2007. A practitioner's approach to estimating intertemporal relationships using longitudinal data: Lessons from applications in wage 
dynamics. In: Heckman, J. J., Leamer, E. (Eds.), Handbook of Econometrics. Vol. 6A of Handbooks in Economics. Elsevier, Amsterdam, Ch. 62, forthcoming.

Mahalanobis, P. C., 1936. On the generalized distance in statistics. Proceedings of the National Institute of Sciences of India 2 (1), 49-55.

Moffitt, R. A., Summer 2003. The negative income tax and the evolution of U.S. welfare policy. Journal of Economic Perspectives 17 (3), 119-140.

Nagin, D. S., 2001. Measuring the economic benefits of developmental prevention programs. Crime and Justice 28, 347-384.

National Center for Education Statistics, 1991. Digest of Education Statistics, 1990. U. S. Department of Education, Washington, D.C.

National Center for Education Statistics, Various. Digest of Education Statistics. National Center for Education Statistics, Washington, DC.

Rodgers, J. D., Brookshire, M. L., Thornton, R. J., 1996. Forecasting earnings using age-earnings profiles and longitudinal data. Journal of Forensic Economics 9 (2), 169-210.

Rolnick, A., Grunewald, R., 2003. Early childhood development: Economic development with a high public return. Tech. rep., Federal Reserve Bank of Minneapolis, Minneapolis, MN. 
Schweinhart, L. J., Barnes, H. V., Weikart, D., 1993. Significant Benefits: The High-Scope Perry Preschool Study Through Age 27. High/Scope Press, Ypsilanti, MI.

Schweinhart, L. J., Montie, J., Xiang, Z., Barnett, W. S., Belfield, C. R., Nores, M., 2005. Lifetime Effects: The High/Scope Perry Preschool Study Through Age 40. High/Scope Press, Ypsilanti, MI.

Shonkoff, J. P., Phillips, D., 2000. From Neurons to Neighborhoods: The Science of Early Child Development. National Academy Press, Washington, DC.

Tax Policy Center, 2007. Individual income tax brackets, 1945-2007.

Tsang, M. C., 1997. The cost of vocational training. International Journal of Manpower $18(1 / 2), 63-89$.

Viscusi, W. K., Aldy, J. E., August 2003. The value of a statistical life: A critical review of market estimates throughout the world. Journal of Risk and Uncertainty 27 (1), 5-76.

Weikart, D. P., Epstein, A. S., Schweinhart, L., Bond, J. T., 1978. The Ypsilanti Preschool Curriculum Demonstration Project: Preschool Years and Longitudinal Results. High/Scope Press, Ypsilanti, MI. 